\title{
Angiotensin Receptor Type 1 Inhibition in Lymphopenia and in Neutropenia After Traumatic Brain Injury In Mice: a Randomized Controlled Study (ATLANTIS)
}

\section{Ralph Timaru-Kast ( $\square$ timaruka@uni-mainz.de)}

University Medical Center of the Johannes Gutenberg University Mainz https://orcid.org/0000-00024676-2858

\section{Shila P. Coronel-Castello}

University Medical Center of the Johannes Gutenberg University Mainz

\section{Tobias Krämer}

University Medical Center of the Johannes Gutenberg University Mainz

\section{André V. Hugonnet}

University Medical Center of the Johannes Gutenberg University Mainz

\section{Michael K.E. Schäfer}

University Medical Center of the Johannes Gutenberg University Mainz

\section{Anne Sebastiani}

University Medical Center of the Johannes Gutenberg University Mainz

Serge C. Thal

University Medical Center of the Johannes Gutenberg University Mainz

\section{Research}

Keywords: angiotensin-II-receptor-type 1, AT1, traumatic brain injury, brain trauma, TBI, neuroinflammation, microglia, neutrophils, lymphocytes, candesartan

Posted Date: November 3rd, 2021

DOl: https://doi.org/10.21203/rs.3.rs-999453/v1

License: (c) (i) This work is licensed under a Creative Commons Attribution 4.0 International License. Read Full License 


\section{Abstract}

Background: Cerebral inflammation with invasion of neutrophils and lymphocytes is an important factor in the process of secondary brain damage expansion after traumatic brain injury (TBI). Depletion of neutrophils in mice has been shown to reduce neurologic impairment after TBI. The intrinsic cerebral renin-angiotensin system is an important mediator of cerebral inflammation, as inhibition of the angiotensin II receptor type 1 (AT1) with candesartan improves neurologic recovery, and reduces secondary brain damage and cerebral neutrophil invasion after TBI. The present study was therefore designed to determine the role of immune cells in AT1 inhibition-mediated neuroprotection after TBI.

Methods: In study A we assessed the effect of neutrophil depletion in mice after TBI. In study B we investigated the impact of RAG1 deficiency (RAG1 ${ }^{-/}$; mice without mature B- and T-lymphocytes) after TBI. In study $\mathrm{C}$ we investigated the role of neutrophils in candesartan mediated protection after TBI in wild-type mice with and without neutrophil depletion. In study D we examined the role of lymphocytes in AT1 inhibition mediated neuroprotection after TBI in RAG1\%.

Results: Neutropenic and RAG ${ }^{-1}$ mice showed reduced brain damage compared to control groups. In control antibody treated wild type mice AT1 inhibition reduced lesion volumes and inflammation compared to vehicle, while in neutropenic mice, candesartan had no effect. In RAG1/- mice AT1 inhibition resulted in reduction of brain damage and neuroinflammation compared to vehicle group.

Conclusion: The present results demonstrate, that reduction of neutrophils and of lymphocytes as well as AT1 inhibition in wild type and RAG $1^{-/}$mice reduce brain damage and inflammation after TBI. However, AT1 inhibition was neuroprotective in RAG $1^{-/-}$mice, but not in neutropenic mice. Therefore, the results indicate that AT1 inhibition mediated neuroprotection may be exerted by anti-inflammatory effects on neutrophils, with a subsequent reduction of neutrophil invasion.

\section{Background}

The most common cause of trauma-related death and severe disability in industrialized countries is traumatic brain injury (TBI) (1). Following the mechanical impact (primary injury), detrimental mechanisms such as cerebral inflammation elicit the expansion of a secondary brain injury into the surrounding healthy tissue (2). The early robust immune response is characterized by the activation of the innate immunity, the brain resident microglia with concomitant tissue infiltration of peripheral immune cells, mainly neutrophils $(3,4)$. The subsequent engagement of the adaptive immune system follows with $B$ and $T$ lymphocyte invasion (3-6). One important mediator of neuroinflammation is angiotensin II (AngII) $(4,7,8)$, the main effector peptide of the intrinsic cerebral renin-angiotensin system (RAS). Activation of Angll receptor type 1 (AT1) mediates vasoconstriction and different pro-inflammatory processes, aggravating secondary brain damage after cerebral insults (8-14). AT1 signaling is mediated by mitogen-activated protein kinases (ERK1/2, JNK, and p38MAPK), glycogen synthase kinase, Rho/ROCK kinase, receptor tyrosine- (PDGF and EGFR) and non-receptor tyrosine-kinases (Src, Pyk2, and 
JAK/STAT) (15). Recent experimental TBI studies have revealed that AT1 inhibition reduced secondary brain damage and improved neurological outcome $(4,8,16,17)$. Alongside reduced microglial activation, in mice treated with the specific AT1 inhibitor candesartan, we detected a reduced infiltration of neutrophils into injured brain tissue (4). Thus, one possible underlying mechanism of AT1 inhibition mediated neuroprotection may be a reduction of neutrophil invasion (4). In order to test this hypothesis, in the present study, we investigated the role of neutrophils and lymphocytes in the context of AT1 inhibition after experimental TBI. To this end, we used wild type mice with or without neutrophil depletion and recombination activating gene 1 - deficient mice $\left(\mathrm{RAG}^{-/-}\right)$, lacking mature $\mathrm{B}$ - and T-lymphocytes. Primary endpoints were secondary brain damage, cerebral inflammation, and neurologic outcome.

\section{Methods}

\subsection{Animals}

In studies A and C, adult male, 8 weeks old, C57/Bl6 mice (wild-type (WT) mice; Charles River Deutschland GmbH; Sulzfeld, Germany) were examined. In Study B and D we investigated male knockout mice lacking RAG1 (RAG1 ${ }^{-/-}$; Translational Animal Research Center of the University Medical Center of the Johannes Gutenberg-University). Mice were randomly assigned to experimental groups (www.pubmed.de/tools/zufallsgenerator). Experiments and analyses were performed by investigators blind towards group allocation and treatment. The studies were performed with the approval of the Animal Care and Ethics Committee of Rhineland-Palatinate, Germany in accordance with the institutional guidelines of the Johannes Gutenberg University, Mainz (protocol number: 23177-07/G13-1-046). The animals were kept under controlled light and environmental conditions (12-h dark/light cycle, $23 \pm 1^{\circ} \mathrm{C}$, $55 \% \pm 5 \%$ relative humidity), and had free access to food (Altromin, Germany) and water at all times before and after the experiments.

\subsection{Experimental TBI and anesthesia}

Animals were anesthetized by intraperitoneal (i.p.) application of midazolam (Hameln pharmaceuticals $\mathrm{GmbH}$; Hameln, Germany), fentanyl (CuraMed, Karlsruhe, Germany) and medetomidine (Dorbene vet; Wien, Austria). An air mixture $\left(40 \% \mathrm{O}_{2}\right.$ and $\left.60 \% \mathrm{~N}_{2}\right)$ was supplied via facemask in spontaneously breathing mice (18). Depth of anesthesia was verified by respiration rate and pedal withdrawal reflexes. Rectal temperature was maintained constant at $37^{\circ} \mathrm{C}$ by feedback-controlled heating pad (Hugo Sachs, Germany). TBI was performed by controlled cortical impact $(\mathrm{CCl})$ as previously described in detail $(8,19)$. Briefly, the animal's head was fixed in a stereotactic frame (Kopf Instruments, USA) and a large craniotomy $(4 \times 4 \mathrm{~mm})$ was drilled above the right parietal cortex between sagittal, lambdoid, coronal sutures and insertion of the temporal muscle. A custom-fabricated controlled pneumatic impactor (L. Kopacz, Mainz, Germany) was placed perpendicularly to the brain surface and the impactor tip (diameter: $3 \mathrm{~mm}$ ) centered in the middle of the craniotomy. The impact parameters were as follows: velocity, $8 \mathrm{~m} / \mathrm{s}$; duration, $150 \mathrm{~ms}$; brain penetration, $1 \mathrm{~mm}$ ). Immediately after $\mathrm{CCl}$, the craniotomy was closed with conventional tissue glue (Histoacryl, Braun-Melsungen, Germany) and filament sutures. After the 


\subsection{Treatment}

\subsubsection{Application of antibodies for neutrophil granulocyte depletion and control antibodies}

For the depletion of neutrophils in WT mice (studies A and C) the Ly6G-specific antibody (clone 1A8) was used. In the control antibody group, we used the isotype control antibody immunoglobulin IgG2a (clone: 2A3). Both antibodies, anti-Ly6G (1A8) and IgG2a (2A3) (BXCell; West Lebanon, USA) were diluted in PBS with a final concentration of $2.5 \mathrm{mg} / \mathrm{mL}$. We injected $0.2 \mathrm{~mL}(0.5 \mathrm{mg})$ of anti-Ly6G antibody (ND) and the same volume of the control IgG2a antibody (Ctrl) intraperitoneally (i.p.) $24 \mathrm{~h}$ before (studies $\mathrm{A}$ and $\mathrm{C}$ ) and $24 \mathrm{~h}$ after experimental TBI (study $\mathrm{C}$ ).

\subsubsection{Application of the AT1 inhibitor candesartan or vehicle solution}

In both studies (C, D) candesartan, a specific AT1 inhibitor was applied. Candesartan (CV-11974; Tocris bioscience; Bristol, UK) and the vehicle solution were prepared and applied as previously described (8): The crystalline form of the active drug candesartan was dissolved prior each set of experiments in 0.037 $\mathrm{M} \mathrm{Na}_{2} \mathrm{CO}_{3}$ (vehicle solution) in a concentration of $10 \mu \mathrm{g} / \mathrm{mL}$. The animals received $0.1 \mathrm{mg} / \mathrm{kg}$ candesartan (Cand) or vehicle solution (Veh) by subcutaneous (s.c.) injection 30 min after experimental TBI, followed by a daily injection, 24 and $48 \mathrm{~h}$ after TBI.

\subsection{Experimental protocols}

\subsubsection{Study A: Effect of neutrophil granulocyte depletion 4 and 24 hours after TBI}

WT mice were randomized to i.p. injection with specific anti-Ly6G (1A8) for neutrophil depletion (ND) or control antibody (Ctrl; IgG2a (2A3)) $24 \mathrm{~h}$ before TBI. Lesion volume and cerebral inflammation were determined $4 \mathrm{~h}$ (ND-4h, Ctrl-4h; $\mathrm{n}=6$ / group) and $24 \mathrm{~h}$ after TBI (ND-24h, Ctrl-24h; $\mathrm{n}=8$ / group). Additionally, neurological outcome was assessed $24 \mathrm{~h}$ after TBI. In mice without TBI, neutrophil depletion was controlled in the blood $24 \mathrm{~h}$ after application (ND-0, Ctrl-0; $\mathrm{n}=2$ / group).

\subsubsection{Study B: Effect of RAG1 deficiency mediated lymphopenia 24 hours and 5 days after TBI}

In RAG1-deficient mice ( $\mathrm{RAG}^{-/-}$) and their $\mathrm{RAG}^{+/+}$wild type litter mates lesion volume and neurology were assessed $24 h$ ( $n=10 /$ group) and 5 days ( $n=8 /$ group) after CCI. 


\subsubsection{Study C: Effect of AT1 inhibition in neutrophil depleted mice 3 days after TBI}

Mice were randomized to treatment ( $24 \mathrm{~h}$ before, and repeated $24 \mathrm{~h}$ after TBI) with either anti-Ly6G (ND) or IgG2a control antibody (Ctrl). They were subjected to $\mathrm{CCl}$ and then randomly assigned to additional treatment with candesartan (Cand) or vehicle solution (Veh), performed $30 \mathrm{~min}$ after TBI and then repeated daily, 24 and $48 \mathrm{~h}$ after TBI. Therefore, the animals were randomly allocated to four treatment groups: Ctrl-Cand, Ctrl-Veh, ND-Cand and ND-Veh ( $n=12$. / group). After the 72-hours observation period, brains were removed for quantification of lesion volume, cytokine expression and activated microglia. Blood samples were withdrawn for hematological quantification of white blood cells (WBC), lymphocytes and neutrophils. For comparison we used naïve (non-operated) WT mice $(n=6)$.

\subsubsection{Study D: Effect of AT1 inhibition in lymphopenic RAG1-deficient mice 3 days after TBI}

RAG1-deficient mice were randomly assigned to candesartan or vehicle solution treatment (RAG1 ${ }^{-/}$Cand, RAG1 ${ }^{-/-}$-Veh; $\mathrm{n}=12$ /group) at $30 \mathrm{~min}, 24$ and $48 \mathrm{~h}$ after TBI. As in study $\mathrm{C}, 72 \mathrm{~h}$ after TBI, lesion volume, cytokine expression and activated microglia were quantified and a hematologic assessment was performed. Additionally, we used naïve RAG1 ${ }^{-/-}$mice $(n=6)$.

\subsection{Measurement of physiological parameters}

Before, and after experimental TBI body weight of each mouse was controlled. Blood pressure was measured 5 minutes before and after $\mathrm{CCl}$ under general anesthesia at the tail using a modified NIBP system (RTBP 2000, Kent Scientific, Torrington, USA; A/D converter: PCI 9112, Adlink Technology, Taiwan; software: Dasylab 5.0, measX, Germany; Flexpro 6.0, Weisang, Germany) as previously described (18). Additionally, blood pressure values were determined in awake animals daily for 8 days before (training phase) and for 2 days after $\mathrm{CCl}$. Perioperative body temperature was measured by a rectal temperature probe (Physitemp; Clifton, NJ, USA).

\subsection{Assessment of functional outcome}

In studies A, C and D neurological outcome was assessed using the rotarod performance test (Heidolph Instruments $\mathrm{GmbH} \& \mathrm{Co}$.; Schwabach, Germany) as previously described (20-23). After a pre-training phase (mice remained on a rotating rod for $20 \mathrm{~s}$ at $4 \mathrm{rpm}$ ) two days before TBI, the time to fall from the accelerating rod in the 2-min test period was registered. This test assesses coordination and motoric function and was performed 1 day before, 24 and $72 \mathrm{~h}$ after $\mathrm{CCl}$. In study B functional outcome was determined by Neurological Severity Score (24). In addition to the rotarod test, in studies C and D, functional outcome was also determined by modified neurological severity score (mNSS; modified after Tsenter et al., 2008 (24)) 1 day before and 24 and 72 hours after $\mathrm{CCl}$ (4). To calculate mNSS, general behavior, alertness, motor ability and balance were rated with 6 different tasks. Each task was scored from 0 (normal) up to 3 (failed task). The mNSS ranges from 0 (healthy) to 16 (severely impaired) points 
(25) (Table 1). All neurological tests were performed by investigators blinded towards experimental group allocations.

Table 1

Modified Neurological Severity Score (mNSS).

\begin{tabular}{|c|c|c|}
\hline & & Points \\
\hline \multirow[t]{4}{*}{ 1. Exit from circle } & $<30 \mathrm{sec}$ & 0 \\
\hline & For $30 \mathrm{sec}$ & 1 \\
\hline & For $60 \mathrm{sec}$ & 2 \\
\hline & $>2 \min$ & 3 \\
\hline \multirow[t]{2}{*}{ 2. Startle reflex } & Present & 0 \\
\hline & Absent & 1 \\
\hline \multicolumn{3}{|c|}{ 3. General behavioral deficit } \\
\hline \multirow[t]{2}{*}{ Seeking behavior } & Present & 0 \\
\hline & Absent & 1 \\
\hline \multirow[t]{2}{*}{ Walk straight } & Present & 0 \\
\hline & Absent & 1 \\
\hline \multicolumn{3}{|l|}{ 4. Coordination } \\
\hline \multicolumn{3}{|c|}{$\begin{array}{l}\text { (Criteria: OP: no impairment; 1P: feet misplacement, unstable; 2P: stops } \\
\text { moving) }\end{array}$} \\
\hline Beam walking $3 \mathrm{~cm}$ & Score & $(0-2)$ \\
\hline Beam walking $1,5 \mathrm{~cm}$ & Score & $(0-2)$ \\
\hline Beam walking $1 \mathrm{~cm}$ & Score & $(0-2)$ \\
\hline \multicolumn{3}{|c|}{ 5. Balance (Criteria: OP: grips stick with 4 paws; $1 \mathrm{P}: 1-4$ paws not gripping) } \\
\hline Round stick & Score & $(0-1)$ \\
\hline Square stick & Score & $(0-1)$ \\
\hline \multicolumn{3}{|l|}{ 6. Motor deficit } \\
\hline \multirow[t]{3}{*}{ Hemiparesis } & Absent & 0 \\
\hline & One Foot & 1 \\
\hline & Present hemiparesis & 2 \\
\hline
\end{tabular}

The modified Neurological Severity Score (mNSS) was designed on the basis of the Neurological Severity Score introduced by Tsenter and colleagues (24). The mNSS focusses on motoric function and 
behavioral deficits and was performed 1 day before $\mathrm{CCl}$ and on posttraumatic day 1 and 3 (day 5 in study C) after experimental TBI.

\subsection{Flow cytometry and blood cell count}

At the end of observation period, in deep anesthesia, EDTA anti-coagulated blood samples were taken from the retro-orbital veins as previously described (26). The differential blood cell count was obtained via flow cytometry with a full automated veterinary analyzer, validated for murine blood analyses (ADVIA 2120i Hematology System; Siemens Healthcare, Erlangen, Germany) by an experimenter blinded to experimental group allocation.

\subsection{Histologic and immunohistochemical evaluation}

According to our previous protocol (4) brains were removed in deep anesthesia. For tissue evaluation, the brains were frozen in powdered dry ice and stored at $-20^{\circ} \mathrm{C}$. They were then cut in coronal plane with a cryostat (HM 560 Cryo-Star, Thermo Fisher Scientific, Walldorf, Germany) as previously described in detail (8). The first slide was defined according to the first section corresponding to bregma $+3.14 \mathrm{~mm}$ in the Mouse Brain Library (www.mbl.org). Sixteen sections (12 and $20 \mu \mathrm{m}$ ) were collected at $500 \mu \mathrm{m}$-intervals, placed on Superfrost+TM slides (Thermo Fisher Scientific, Germany). In cresyl violet (Merck, Darmstadt, Germany) stained sections $(12 \mu \mathrm{m})$, the total area of both hemispheres and the injured brain tissue area were determined for each section and animal using a computerized image analysis system (Delta Pix Insight; Maalov, Denmark) by an investigator blind to the group allocation. The total hemispheric brain volumes and the lesion volumes were calculated by following formula: 0.5 [mm] x (area of slide 1 [mm²] + area of slide $2\left[\mathrm{~mm}^{2}\right]+\ldots+$ area of slide $\left.16\left[\mathrm{~mm}^{2}\right]\right)(4,8)$. Immunohistochemistry was performed as described before (25). For immunohistochemical staining, cryosections (20 $\mu \mathrm{m})$ were fixed in $4 \%$ paraformaldehyde in phosphate buffered saline (PBS), incubated with blocking solution containing serum (5 \% goat serum, 2 \% bovine serum albumin, Gibco) and 0.1\% TX-100 (Sigma) in PBS for $1 \mathrm{~h}$ at room temperature. Primary antibodies specific for anti-ionized calcium-binding adapter molecule-1 (Iba-1; rabbit anti-mouse, anti-lba-1 antibody; Wako Chemicals $\mathrm{GmbH}$, Neuss, Germany) were applied in blocking solution overnight at $4^{\circ} \mathrm{C}$. The sections were washed, incubated with secondary biotin-conjugated antibodies (goat anti-rabbit lgG; Merck; Darmstadt, Germany) and processed according to the manufacturer's instructions using Vectastain Elite ABC Kit (Vector Laboratories, Burlingame, USA). Images were taken at $\times 20$ magnification (Axiovert, Zeiss, Germany). The total number of positive cells were counted at bregma $-1.28 \mathrm{~mm}$ in a region of interest (ROI) of $0.52 \times 0.65 \mathrm{~mm}^{2}$ in the cortical tissue adjacent to the lesion by an investigator blind to randomization, using ImageJ software (National Institutes of Health, USA). Activated microglia were identified as lba1-immunolabeled cells with bushyround shaped morphology with phagocytic, amoeboid appearance (27). Results are presented in number of activated Iba-1 positive cells / $\mathrm{mm}^{2}$.

\subsection{Gene expression analysis}

Brain tissue samples from the lesion and perilesional area of $500 \mu \mathrm{m}$ coronal cryostat sections between histologic slice intervals were collected, snap frozen in liquid nitrogen, stored at $-80^{\circ} \mathrm{C}$. As described 
previously in detail $(4,28)$, after tissue sampling, extraction of mRNA and CDNA synthesis qPCR were performed (lysis: Qiazol-reagent, Qiagen, Hilden, Germany; homogenization: MM300 mill mixer, Retsch, Haan, Germany; RNA isolation: RNeasy Lipid Tissue Kit, Qiagen, Hilden, Germany; RNA concentration determined by spectrometer: NanoVue System, GE Healthcare Europe, Munich, Germany; RNA to cDNA reverse transcription Verso cDNA Kit, ABgene, Hamburg, Germany; cDNA amplification: real-time Ligthcycler 480 PCR System, Roche). PCR fragments of all applied genes were generated by PCR on an Eppendorf Thermocycler gradient (Eppendorf, Hamburg, Germany). The PCR products were purified with QIA quick PCR Purification Kit (Qiagen) according to the manufacturer's instructions, and the DNA concentration was determined using NanoVue. A standard curve for absolute quantification was generated with PCR DNA for each PCR product ( $10^{1}-10^{7}$ DNA copies $\left./ \mu \mathrm{l}\right)$, showing similar and good efficiency (90-110\%; LightCycler Software, Roche) and linearity. Equal amounts of cDNA (1 $\mu \mathrm{l})$ of each sample were analyzed in duplicates and amplified by real-time Lightcycler 480 PCR System (Roche). Real-time RT PCR kits were used according to the manufacturer's instructions. All assays were carried out by an investigator blinded to group allocation. Using mouse-specific primers and probes (Table 2) and optimized temperature conditions for $\mathrm{qPCR}$, absolute copy numbers of the target genes, tumor necrosis factor a (TNFa), transforming growth factor $\beta$ (TGF $\beta$ ), interleukin $1 \beta$ (IL1 $\beta$ ), interleukin 6 (IL6) and inducible nitric oxide synthase (iNOS) were calculated, and were then normalized against the absolute copy numbers of cyclophilin A (PPIA) $(4,6,8,29)$. The reference gene PPIA was chosen as single normalizer (30) based on recent findings in our housekeeping gene study (29). In order to improve comparability of the mRNA expression data between different treatment groups and to eliminate qPCR kit dependent differences and limitations, QPCR data was normalized with PPIA and then related to normalized naïve target gene expression from naïve tissue samples from the corresponding brain region (31). Therefore, normalized target gene expression values are expressed as \% naïve expression (4). 
Table 2

Primers for the quantitative real-time PCR

\begin{tabular}{|c|c|c|}
\hline PCR assay & \multirow[t]{2}{*}{ Oligonucleotide Sequence $\left(5^{\prime}-3^{\prime}\right)$} & GenBank \\
\hline (amplicon size) & & No. \\
\hline \multirow[t]{2}{*}{ PPIA (146 bp) } & F: 5'-GCGTCTSCTTCGAGCTGTT-3' & \multirow[t]{2}{*}{ NM_008907 } \\
\hline & R: 5'-RAAGTCACCACCCTGGCA-3' & \\
\hline \multirow[t]{2}{*}{ IL1 $\beta$ (348 bp) } & F: 5'-GTGCTGTCGGACCCATATGAG-3' & \multirow[t]{2}{*}{ NM_008361 } \\
\hline & R: 5'-CAGGAAGACAGGCTTGTGCTC-3' & \\
\hline \multirow[t]{2}{*}{ IL6 (471 bp) } & F: 5'-TCGTGGAAATGAGAAAAGAGTTG -3' & \multirow[t]{2}{*}{ NM_031168 } \\
\hline & R: 5'-TATGCTTAGGCATAACGCACTAG -3' & \\
\hline \multirow[t]{2}{*}{ TNFa (212 bp) } & F: 5'-TCTCATCAGTTCTATGGCCC -3' & \multirow[t]{2}{*}{ NM_013693 } \\
\hline & R: 5'-GGGAGTAGACAAGGTACAAC -3' & \\
\hline \multirow[t]{2}{*}{ TGF $\beta$ (142 bp) } & F: 5'-CTTCAATACGTCAGACATTCGGG-3' & \multirow[t]{2}{*}{ NM_011577 } \\
\hline & R: 5'-GTAACGCCAGGAATTGTTGCTA-3' & \\
\hline \multirow[t]{2}{*}{ iNOS (312 bp) } & F: 5'-TGTGTCAGCCCTCAGAGTAC-3' & \multirow[t]{2}{*}{ NM_010927 } \\
\hline & R: 5'-CACTGACACTYCGCACAA -3' & \\
\hline
\end{tabular}

Mouse specific primers and probes for quantitative real-time polymerase chain reaction (qPCR):

cyclophilin A (PPIA), interleukin $1 \beta$ (IL1 $\beta$ ), interleukin 6 (IL6), tumor necrosis factor a (Tnfa), transforming growth factor $\beta$ (TGF $\beta$ ) and inducible nitric oxide synthase (iNos); F: forward, R: reverse.

\subsection{Statistical analysis}

All experiments were randomized and performed by investigators blinded toward the treatment groups (computer-based randomization: www.pubmed.de/tools/zufallsgenerator). To determine the required sample size, an a priori power analysis using $\mathrm{G} *$ Power was performed, with lesion volume data from previously published studies (32). The a priori power analysis was performed to determine an effect size of 0.7 , standard statistical power $(1-\beta)$ of 0.95 , and a significance level (a) of 0.05 . Statistical analysis was performed using the GraphPad Prism 8 Statistical Software (GraphPad Software Inc., La Jolla, CA, USA). Data distribution was tested by Shapiro-Wilks test. The comparison of parametric and nonparametric data between two independent groups was done using the Welch-t test and the Wilcoxon rank sum test, respectively. In this multi-arm parallel group randomized trial, for comparison of multiple independent groups, if the Shapiro-Wilk normality test was passed, one-way analysis of variance (oneway ANOVA) with post-hoc Holm-Šidák comparisons test (comparisons between all groups) was employed. In experimental groups where two separate treatment factors (neutrophil depletion and AT1 inhibition) are present, a two-way analysis of variance (two-way ANOVA) was performed. Physiologic data, blood cell count, lesion volumes, number of activated microglia and mRNA expression data were 
compared between experimental groups with two-way ANOVA and post hoc with all-pairwise multiple comparison procedures (Holm-Šidák method). To evaluate group differences in repeated measurements from the same animals (body weight, systolic blood pressure), repeated measures (RM) two-way ANOVA (two-factor repetition) was applied (factors: treatment and time), followed by Šidák's multiple comparisons test. Whenever there were missing values in the repeated measures dataset and a two-way ANOVA was not possible, repeated measures (mNSS, rotarod) data were analyzed with the mixed effect model using the restricted maximum likelihood (REML) method with Holm Šidák's multiple comparison test. The $p$ values were adjusted for multiple comparisons. Values of $p<0.05$ were considered significant. Data sets were tested for statistically significant outliers using the Grubbs' test. Data are presented as mean and standard deviation (mean $\pm \mathrm{SD}$ ).

\section{Results}

\subsection{Perioperative physiological parameters were stable in all groups.}

Peri- and intraoperative body temperature and systolic blood pressure were in all mice within physiological range and there was no considerable difference between groups (Tab. 4). As published earlier, in our standardized anesthesia and operation setting, values were stable and within normal physiological limits (6): arterial blood gases analyzed $15 \mathrm{~min}$ after $\mathrm{CCl}$ under general anesthesia in WT mice (ABL800 Basic, Radiometer Medical ApS, Brønshøj, Denmark): pH: $7.32 \pm 0.04, \mathrm{p}_{\mathrm{a}} \mathrm{O}_{2}: 272 \pm 21$, $\mathrm{p}_{\mathrm{a}} \mathrm{CO}_{2}: 48 \pm 4 \mathrm{mmHg}(6)$.

\subsection{After TBI bodyweight was not affected by anti-Ly6G, RAG1-deficiency or AT1 inhibition.}

In naïve mice bodyweight was $24.7 \pm 2.2 \mathrm{~g}$. Before TBI, initial bodyweight was in Ctrl-4h mice $25.6 \pm 0.9 \mathrm{~g}$ and in ND-4h mice $25.5 \pm 1.1 \mathrm{~g}$. In ND-24h mice bodyweight was reduced in both treatment groups, without difference between Ctrl and ND (before TBI: $25.8 \pm 0.7$ and $26.0 \pm 1.2 \mathrm{~g} ; 24$ hours after TBI: $24.1 \pm$ $1.2^{\star}$ and $24.3 \pm 1.3^{*}$, for Ctrl and ND, respectively, ${ }^{*}<<0.001$ vs. before TBI). The body weight of RAG $1^{+/+}$ and $\mathrm{RAG}^{-/-}$were similarly reduced after $\mathrm{CCl}$ (24-hours investigation: before TBI: $22.7 \pm 0.8$ and $24.2 \pm$ $1.9 \mathrm{~g} ; 24$ hours after TBI: $20.3 \pm 1.2^{*}$ and $21.5 \pm 1.7^{*}$, for $\mathrm{RAG}^{+/+}$and $\mathrm{RAG} 1^{-/{ }^{-}}$, respectively, ${ }^{*}<0.001$ vs. before TBI). In the second, 5 -days investigation, after a body weight loss at 1 day after $\mathrm{CCl}, \mathrm{RAG} 1^{+/+}$and $\mathrm{RAG}^{-/-}$animals regained weight at 5 days after $\mathrm{CCl}$ in both groups (before TBI: $22.4 \pm 1.1$ and $22.2 \pm 1.2$ g, 1 day after TBI: $20.6 \pm 1.2^{\star \#}$ and $20.4 \pm 0.5^{\star \#}$ and 5 days after TBI: $22.3 \pm 0.9$ and $21.8 \pm 1.5$, for $\mathrm{RAG}^{+/+}$and $\mathrm{RAG}^{-/-}{ }^{-}$, respectively, ${ }^{*} \mathrm{p}<0.001$ vs. before TBI and ${ }^{*} \mathrm{p}<0.0011$ vs. 5 days after TBI). However, in both investigations RAG1 deficiency did not affect posttraumatic body weight loss (Tab. 3). In all groups there is a significant posttraumatic decrease of bodyweight with a minimum on day 2 and an increase on day 3. However, neither neutrophil depletion, nor RAG1 deficiency, nor AT1 inhibition 
affected posttraumatic body weight loss compared to control antibody, wild type or vehicle solution treated mice (Tab. 3).

Table 3

Pre- and postoperative body weight development

\begin{tabular}{|c|c|c|c|c|}
\hline $\begin{array}{l}\text { Time / parameter } \\
\text { Groups }\end{array}$ & $\begin{array}{l}\text { Bodyweight [g] } \\
\text { before TBI }\end{array}$ & $\begin{array}{l}\text { Bodyweight [g] } \\
24 \text { hours after TBI }\end{array}$ & $\begin{array}{l}\text { Bodyweight [g] } \\
48 \text { hours after TBI }\end{array}$ & $\begin{array}{l}\text { Bodyweight [g] } \\
72 \text { hours after TBI }\end{array}$ \\
\hline Ctrl-Veh & $24.9 \pm 1.3$ & $23.4 \pm 1.6^{*}$ & $23.4 \pm 1.2^{\star}$ & $24.2 \pm 1.1 *, \$, \#$ \\
\hline Ctrl-Cand & $24.5 \pm 2.0$ & $23.1 \pm 2.1^{*}$ & $23.1 \pm 2.0 *$ & $23.9 \pm 2.1 *, \$$ \\
\hline ND-Veh & $24.8 \pm 1.9$ & $23.3 \pm 1.7 *$ & $23.3 \pm 1.4^{*}$ & $24.1 \pm 1.5^{\star, \$, \#}$ \\
\hline ND-Cand & $24.8 \pm 0.8$ & $23.1 \pm 0.8^{*}$ & $22.9 \pm 0.8^{*}$ & $23.9 \pm 0.8^{*, \$, \#}$ \\
\hline RAG1-/--Veh $^{-}$ & $24.0 \pm 2.3$ & $23.6 \pm 2.3^{*}$ & $22.9 \pm 2.1 *, \$$ & $23.5 \pm 2.2^{\star, \#}$ \\
\hline RAG1-/--Cand & $23.9 \pm 2.9$ & $23.3 \pm 3.0 *$ & $22.4 \pm 2.8^{*, \$}$ & $23.3 \pm 2.7^{*, \#}$ \\
\hline
\end{tabular}

Bodyweight was assessed before induction of anesthesia and experimental TBI and 24, 48 and 72 hours after TBI ( ${ }^{*} p<0.05$ vs. before TBl; ${ }^{\$} p<0.05$ vs. $24 \mathrm{~h}$ after TBl; ${ }^{\#} p<0.05$ vs. 48 hours after TBI).

\subsection{Low-dose candesartan treatment did not influence blood pressure after CCl.}

In general, the specific AT1 antagonist candesartan is clinically used for the treatment of arterial hypertension. Therefore, we determined its influence on arterial blood pressure. In the present study, low dose $(0.1 \mathrm{mg} / \mathrm{kg})$ candesartan was applied, which was shown not to alter blood pressure in previous studies $(4,8)$. During the time after $\mathrm{CCl}$ in all experimental treatment groups, blood pressure was within physiological range and was not affected by repeated low-dose candesartan $(0.1 \mathrm{mg} / \mathrm{kg})$ treatment (Tab. 4). 
Table 4

Systolic blood pressure after TBI

\begin{tabular}{|c|c|c|c|c|}
\hline Treatment groups & $0(\mathrm{CCl})$ & $6 \mathrm{~h}$ & $24 \mathrm{~h}$ & $36 \mathrm{~h}$ \\
\hline Ctrl - Vehicle & $119 \pm 17$ & $112 \pm 15$ & $123 \pm 12$ & $114 \pm 13$ \\
\hline Ctrl - Candesartan & $111 \pm 14$ & $106 \pm 22$ & $120 \pm 14$ & $112 \pm 19$ \\
\hline ND - Vehicle & $101 \pm 17$ & $104 \pm 17$ & $128 \pm 22$ & $122 \pm 18^{\S}$ \\
\hline ND - Candesartan & $112 \pm 17$ & $102 \pm 15$ & $145 \pm 5^{\#, \$}$ & $133 \pm 21^{\$}$ \\
\hline RAG1-/- - Vehicle $^{-1}$ & $113 \pm 21$ & $112 \pm 13$ & $136 \pm 16$ & $112 \pm 22$ \\
\hline RAG1 ${ }^{-/-}$- Candesartan & $110 \pm 11$ & $112 \pm 15$ & $119 \pm 16$ & $117 \pm 23$ \\
\hline \multicolumn{5}{|c|}{$\begin{array}{l}\text { Systolic blood pressure [mmHg] during } 36 \text { posttraumatic hours was within physiologic range and no } \\
\text { affected by low dose candesartan treatment. Time point } 0 \text { represents intraoperative measurement } \\
\text { immediately after CCl induction under general anesthesia (in italic characters). At the following time } \\
\text { points, measurements were performed in awake animals (normal characters). At certain time points } \\
\text { there were significant differences, intergroup ( }{ }^{\#} p<0.05 \text { ND-Cand vs. Ctrl-Cand) and within the groups } \\
\text { (ND-Veh: } \$ p<0.05 \text { vs. } 0 \text { (CCl); ND-Cand: }{ }^{\$} p<0.05 \text { vs. } 6 \mathrm{~h} \text { ). }\end{array}$} \\
\hline
\end{tabular}

Differential blood cell counts were performed (Tab. 5). In animals without TBI, neutrophils were reduced from $10.8 \pm 4.1 \%\left(0.64 \pm 0.25 \times 10^{3}\right.$ cells / $\left.\mu \mathrm{L}\right)$ in naïve WT mice to $2.9 \pm 0.4 \%\left(0.15 \pm 0.01 \times 10^{3}\right.$ cells / $\mu \mathrm{L} ; \mathrm{ND}-0)$ in anti-Ly6G (1A8), compared to control antibody treated mice (IgG2A;2A3): $10.1 \pm 1.3 \%$ (0.61 \pm $0.30 \times 10^{3}$ cells / $\left.\mu \mathrm{L} ; \mathrm{Ctrl}-0\right)$. In Ctrl-mice WBC were reduced 4 hours after TBI by $40 \%$ (Ctrl-4h). However, 24 hours (Ctrl-24h) and 72 hours after TBI (Ctrl-Veh and Ctrl-Cand) WBC values corresponded to the initial naïve values. In ND-mice WBC reduction was more distinct and sustaining (ND-4h and-24h), with lasting relatively low WBC count to day 3 after TBI (ND-Veh and ND-Cand). In non-neutrophil-depleted mice, after $\mathrm{TBI}$ as a response to injury stress, there was a shift from lymphocyte-dominated (84 \%) WBC to a significant and sustaining elevation of the neutrophil fraction from $11 \%$ (naïve) to 43,29 and $16 \%$ in Ctrltreated mice 4, 24 and 72h after TBI, respectively. In ND mice, in contrast, after TBI there is no initial elevation of neutrophils. Moreover, 24 and $72 \mathrm{~h}$ after TBI there is a significant neutropenia in ND-mice alongside relatively elevated lymphocyte counts. However, candesartan did not affect neutrophil counts (Tab. 5, Studies A and C). Naïve RAG $1^{-/-}$mice are leukopenic, reduced lymphocyte counts (40\%) are compensated by elevated neutrophil numbers (34\%). After TBI in RAG1 ${ }^{-/-}$mice there is a marked decrease of WBC in vehicle treated mice, whereas in candesartan treated mice the decrease is not significant. In RAG1 $1^{-/-}$there is also a decrease of lymphocytes (25\%) and an increase of neutrophils to $50 \%$, after TBI, that are not affected by AT1 inhibition (Tab. 5, Study D). There is a sustaining posttraumatic decrease of monocytes in all groups. In candesartan treated ND mice, however there is a normalization of monocyte count 3 days after TBI (Tab. 5). At 4 hours after TBI there is an elevation of 
hemoglobin alongside with hematocrit increase. However, 24 and 72 hours after $\mathrm{TBI}$, hematocrit and $\mathrm{Hb}$ are normalized in all groups (Tab. 5). Platelets were within a physiological range in all groups at all time points and not affected by the treatment (Tab. 5).

Table 5: Blood cell count

\section{Study A}

\begin{tabular}{|c|c|c|c|c|c|}
\hline & naïve & Ctrl-4h & ND-4h & Ctrl-24h & ND-24h \\
\hline $\begin{array}{l}\text { White blood cells }\left(\times 10^{3} \mathrm{n} /\right. \\
\mu \mathrm{L})\end{array}$ & $5.7 \pm 0.6$ & $3.4 \pm 1.0^{\star}$ & $2.2 \pm 0.4^{\star \star}$ & $4.6 \pm 1.6$ & $3.5 \pm 0.9 *$ \\
\hline Neutrophils (\%) & $10.8 \pm 4.1$ & $\begin{array}{l}43.4 \pm \\
5.9 * \star\end{array}$ & $\begin{array}{l}15.2 \pm \\
3.0^{\# \#}\end{array}$ & $28.5 \pm 12.3^{\star \S}$ & $4.8 \pm 1.3^{\# \#}$ \\
\hline Lymphocytes (\%) & $83.6 \pm 3.6$ & $\begin{array}{l}52.4 \pm \\
6.0 * \star\end{array}$ & $\begin{array}{l}80.1 \pm \\
2.6^{\# \#}\end{array}$ & $\begin{array}{l}65.6 \pm \\
11.1^{1 * \star \S}\end{array}$ & $\begin{array}{l}90.2 \pm \\
2.1 \# \#\end{array}$ \\
\hline Monocytes (\%) & $1.0 \pm 0.2$ & $0.5 \pm 0.2^{\star}$ & $0.4 \pm 0.2^{\star \star}$ & $0.7 \pm 0.2^{\star}$ & $0.5 \pm 0.1^{\star \star}$ \\
\hline Hemoglobin $(\mathrm{g} / \mathrm{dL})$ & $14.7 \pm 1.2$ & $16.2 \pm 0.9$ & $17.3 \pm 0.4^{\star \star}$ & $15.2 \pm 0.8$ & $\begin{array}{l}14.8 \pm \\
0.6 \S \S\end{array}$ \\
\hline Platelets $\left(x 10^{3} \mathrm{n} / \mu \mathrm{L}\right)$ & $1277 \pm 125$ & $1130 \pm 117$ & $1000 \pm 70$ & $1115 \pm 220$ & $\begin{array}{l}1087 \pm \\
125\end{array}$ \\
\hline
\end{tabular}

\section{Study C}

\begin{tabular}{|c|c|c|c|c|c|}
\hline & naïve & Ctrl-Veh & Ctrl-Cand & ND-Veh & ND-Cand \\
\hline $\begin{array}{l}\text { White blood cells }\left(\times 10^{3} \mathrm{n} /\right. \\
\mu \mathrm{L})\end{array}$ & $5.7 \pm 0.6$ & $4.2 \pm 1.1$ & $4.6 \pm 1.3$ & $3.9 \pm 0.8^{*}$ & $3.6 \pm 1.0 *$ \\
\hline Neutrophils (\%) & $10.8 \pm 4.1$ & $\begin{array}{l}16.0 \pm \\
3.0^{*}\end{array}$ & $15.2 \pm 2.7 *$ & $\begin{array}{l}6.2 \pm \\
2.1^{*}\end{array}$ & $\begin{array}{l}5.2 \pm \\
1.8^{\star}\end{array}$ \\
\hline Lymphocytes (\%) & $83.6 \pm 3.6$ & $\begin{array}{l}78.5 \pm \\
2.5^{*}\end{array}$ & $80.3 \pm 2.6$ & $\begin{array}{l}88.4 \pm \\
4.5^{\# \#}\end{array}$ & $\begin{array}{l}87.3 \pm \\
3.4^{\# \#}\end{array}$ \\
\hline Monocytes (\%) & $1.0 \pm 0.2$ & $\begin{array}{l}0.4 \pm \\
0.2^{\star \star}\end{array}$ & $0.5 \pm 0.2^{\star *}$ & $0.5 \pm 0.3^{\star \star}$ & $0.7 \pm 0.3^{\#, \$}$ \\
\hline Hemoglobin ( $g / d L)$ & $14.7 \pm 1.2$ & $14.4 \pm 0.7$ & $14.2 \pm 1.0$ & $15.2 \pm 0.8$ & $14.4 \pm 0.8$ \\
\hline Platelets $\left(x 10^{3} \mathrm{n} / \mu \mathrm{L}\right)$ & $\begin{array}{l}1277 \pm \\
125\end{array}$ & $1253 \pm 99$ & $\begin{array}{l}1377 \pm \\
131\end{array}$ & $1124 \pm 129$ & $1234 \pm 191$ \\
\hline
\end{tabular}




\begin{tabular}{|c|c|c|c|}
\hline & RAG1 $^{-/-}$naïve & RAG1-/--Veh & $\mathrm{RAG1}^{-/-}$-Cand \\
\hline White blood cells $\left(x 10^{3} \mathrm{n} / \mu \mathrm{L}\right)$ & $1.3 \pm 0.6$ & $0.7 \pm 0.3^{*}$ & $0.9 \pm 0.3$ \\
\hline Neutrophils (\%) & $33.7 \pm 5.2$ & $44.5 \pm 8.9 *$ & $50.0 \pm 6.4^{\star \star}$ \\
\hline Lymphocytes (\%) & $40.3 \pm 5.6$ & $25.3 \pm 3.5^{\star \star}$ & $25.7 \pm 5.2^{\star \star}$ \\
\hline Monocytes (\%) & $4.0 \pm 0.5$ & $1.4 \pm 0.6^{\star \star}$ & $1.3 \pm 0.7^{\star \star}$ \\
\hline Hemoglobin (g/dL) & $15.1 \pm 0.6$ & $14.5 \pm 0.5^{\star}$ & $14.4 \pm 0.4^{\star}$ \\
\hline Platelets $\left(x 10^{3} \mathrm{n} / \mu \mathrm{L}\right)$ & $1404 \pm 100$ & $1476 \pm 79$ & $1499 \pm 145$ \\
\hline
\end{tabular}

Routine differential blood cell count was performed in the laboratories of the Institute of Clinical Chemistry and Laboratory Medicine, University Medical Center of Johannes Gutenberg-University Mainz

\subsection{Study A: Effect of Neutrophil granulocyte depletion}

\subsection{1: Neutrophil granulocyte depletion reduced lesion volume 24 hours after TBI}

Lesion volume was assessed 4 hours and 24 hours after $\mathrm{CCl}$ in Nissl-stained sections. In control antibody treated mice, lesion volume increased from $32.9 \pm 10.0 \mathrm{~mm}^{3}(21.0 \pm 6.5 \%$ contralateral hemisphere volume, \%-clh) at 4 hours, to $43.6 \pm 7.8 \mathrm{~mm}^{3}(27.7 \pm 5.8 \%$-clh $)$ at 24 hours after TBI $(p<0.05)$. In mice treated with anti-Ly6G, there was no increase in lesion volume at 24 hours $\left(29.2 \pm 2.8 \mathrm{~mm}^{3} ; 18.7 \pm 1.7 \%\right.$ clh) compared to 4 hours after TBI $\left(31.7 \pm 3.2 \mathrm{~mm}^{3} ; 20.1 \pm 2.5 \%\right.$-clh $)$. Moreover, neutrophil depletion reduced the lesion volume 24 hours after TBI compared to control group by $33 \%(p<0.05$, Fig. $1 \mathrm{~A})$.

\subsection{2: Neutrophil granulocyte depletion reduced cerebral inflammation}

Number of Iba-1 positive activated microglia was assessed at bregma $-1.28 \mathrm{~mm}$ in the cortical perilesional tissue in a ROI $\left(0.52 \times 0.65 \mathrm{~mm}^{2}\right)$ adjacent to the injury. Results are expressed as number of activated Iba-1 positive cells / $\mathrm{mm}^{2}$. Compared to 4 hours after TBI $\left(\mathrm{n}=117 \pm 11 / \mathrm{mm}^{2}\right)$, there was a slight decrease of activated microglia 24 hours after TBI in control mice $\left(n=98 \pm 14 / \mathrm{mm}^{2} ; p<0.05\right)$. However, neutrophil depletion did not affect microglial activation in the first 24 hours after TBI (Fig. 1B). Additionally, gene expressions were determined by qPCR, normalized to PPIA. Normalized naïve expressions were: IL1 $\beta$ : $0.00197 \pm 0.00044 \mathrm{mRNA}$ /PPIA; IL6: $0.06063 \pm 0.01640 \mathrm{mRNA} / \mathrm{PPIA}$; TNFa: $2.3488 \pm 1.3114 \times 10^{-6}$ mRNA/PPIA; TGF $\beta$ : $0.00560 \pm 0.00078$ mRNA/PPIA; iNOS: $0.00141 \pm 0.00034$ mRNA/PPIA. The gene expressions of experimental groups are expressed as $\%$ normalized naïve expression. In mice without experimental TBI there was no difference in gene expressions between treatment groups (e.g. IL1ß: $87 \pm 10$ and $90 \pm 5$, \% naïve gene expression for Ctrl-0 and ND-0, respectively). Within the first 24 hours after $\mathrm{TBI}$, gene expressions increased significantly in all groups. 
Though, posttraumatic expressions of IL1 $\beta$, IL6, TGF $\beta$ and iNOS did not differ between treatment groups. Posttraumatic increase of TNFa expression, however, was different. At 4 hours after TBI TNFa expression (9969 \pm 3211 \% naïve) was significantly higher in Ctrl than in ND (5771 $\pm 2024 \%$ naïve, $p<0.05$; Fig. 1D). However, at 24 hours after TBI TNFa expressions were similar in both treatment groups (Ctrl: $5151 \pm 783$ and ND: $4096 \pm 748 \%$ naïve, Fig. 1D).

\subsection{3: Neutrophil granulocyte depletion did not affect neurological outcome}

Neurological outcome was assessed before and 24 hours after TBI by rotarod performance test. One day after TBI there was a marked neurological impairment in both groups (from $89 \pm 15$ and $78 \pm 12 \mathrm{~s}$ before TBI to $38 \pm 14$ and $38 \pm 8 s$ at 24 hours after TBI, for Ctrl and ND, respectively, $p<0.001)$. However, neutrophil depletion did not alter neurological outcome compared to control group (Fig. 1C).

\subsection{Study B: Effect of Lymphopenia in RAG1 deficient mice}

3.6.1 Lesion volume in RAG1 ${ }^{-/-}$mice was reduced 1 and 5 days after TBI compared to RAG $1^{+/+}$.

Lesion volume was assessed in $\mathrm{RAG}^{-/-}$mice and their RAG1 ${ }^{+/+}$(wild type) litter mates in Nissl-stained sections. In $\mathrm{RAG1}^{-/-}$mice 24 hours after TBI lesion volume was reduced $\left(27.1 \pm 4.1 \mathrm{~mm}^{3} ; 16.1 \pm 2.4 \%\right.$ clh) by $17 \%$ compared to RAG $1^{+/+}\left(32.4 \pm 5.6 \mathrm{~mm}^{3} ; 19.4 \pm 2.8 \%\right.$-clh; $\mathrm{p}<0.05 ;$ Fig. $\left.2 \mathrm{~A}\right)$. Similarly, five days after TBI compared to $\mathrm{RAG}^{+/+}\left(13.9 \pm 1.0 \mathrm{~mm}^{3} ; 9.1 \pm 0.7 \%\right.$-clh $)$ lesion volume was reduced by $16 \%$ in $\mathrm{RAG}^{-/-}\left(11.8 \pm 1.2 \mathrm{~mm}^{3} ; 7.6 \pm 0.7 \%\right.$-clh; $\mathrm{p}<0.05$; Fig. $\left.2 \mathrm{~B}\right)$.

\subsubsection{Neurological impairment was not affected by RAG1 deficiency}

Neurological Severity Score (after Tsenter and coworkers (24)), assessed one day before and 1 and 5 days after $\mathrm{CCl}$ was not affected in $\mathrm{RAG} 1^{+/+}$compared to $\mathrm{RAG} 1^{-/-}$mice (before TBI: $0 \pm 1$ and $0 \pm 1,1$ day after TBI: $5 \pm 2 *$ and $4 \pm 2^{*}$ and 5 days after TBI: $2 \pm 2^{\#}$ and $2 \pm 1^{\#}$, for $\mathrm{RAG} 1^{+/+}$and $\mathrm{RAG} 1^{-/-}$, respectively, ${ }^{*} p<0.05$ vs. before TBI and ${ }^{\#} p<0.05$ vs. 1 day after TBI).

\subsection{Study C: Effect of Neutrophil granulocyte depletion combined with AT1 inhibition}

\subsection{1: AT1 inhibition had no effect on neutrophil blood cell count.}

To analyze an independent effect of candesartan treatment on neutrophil blood cell count we compared all treatment groups by two-way-ANOVA. While a sustained neutrophil depletion was achieved by antiLy6G, AT1 inhibition did not affect neutrophil granulocyte count (Fig. 3A).

3.7.2: AT1 inhibition reduced lesion volume in control antibody treated mice, while it had no effect in neutrophil granulocyte depleted mice. 
Lesion volume was assessed 72 hours after $\mathrm{CCl}$ in Nissl-stained sections. In candesartan and control antibody treated mice lesion volume $\left(23.9 \pm 3.3 \mathrm{~mm}^{3}\right.$, i.e. $15.3 \pm 1.8 \%$-clh $)$ was significantly reduced compared to vehicle and control antibody treated mice (lesion volume: $27.5 \pm 2.9 \mathrm{~mm}^{3}, 18.5 \pm 1.6 \%$-clh; p $<0.05$; Fig. 3B). In anti-Ly6G treated mice, however, AT1 inhibition had no effect on lesion volume (NDVeh: $26.6 \pm 3.9 \mathrm{~mm}^{3}, 16.4 \pm 3.0 \%$-clh compared to ND-Cand: $24.1 \pm 2.4 \mathrm{~mm}^{3}, 15.7 \pm 2.2 \%$-clh; Fig. 3B).

3.7.3: AT1 inhibition reduced cerebral inflammation in control antibody treated mice, while it had no effect in neutrophil granulocyte depleted mice.

We quantified the number of perilesional activated Iba-1 positive cells as a marker for microglia activation 3 days after TBI. Activated microglia was assessed at bregma $-1.28 \mathrm{~mm}$ in cortical perilesional tissue in a ROI $\left(0.52 \times 0.65 \mathrm{~mm}^{2}\right)$ adjacent to the injury (Figure 5). Results are expressed as number of activated Iba- 1 positive cells / mm². Compared to naïve lba-1 positive cell count $\left(\mathrm{n}=80 \pm 15 / \mathrm{mm}^{2}\right) 72$ hours after TBI there was a highly significant increase of activated microglia in all groups $(p<0.001)$. In control antibody and candesartan treated mice (Ctrl-Cand) activated microglia was reduced $(n=262 \pm 23$ $\left./ \mathrm{mm}^{2}\right)$ compared to Ctrl-Veh $\left(\mathrm{n}=299 \pm 21 / \mathrm{mm}^{2}, \mathrm{p}<0.001\right.$; Fig. 3C). However, in neutrophil depleted mice AT1 inhibition had no effect on activated microglia (ND-Veh: $277 \pm 27$ and ND-Cand: $275 \pm 16 / \mathrm{mm}^{2}$ ). In vehicle treated mice there was a strong tendency towards lower activated microglia count in anti-Ly6Gtreated mice (ND-Veh), compared to Ctrl-Veh ( $p=0.05$; Fig. 3C).

Three days after TBI gene expressions were assessed by $\mathrm{QPCR}$, normalized with PPIA and expressed as \% normalized naïve expressions (IL1ß: $0.00197 \pm 0.00044$, IL6: $0.06063 \pm 0.01640$, TNFa: $2.3488 \pm 1.3114$ x $10^{-6}$, TGF $\beta$ : $0.00560 \pm 0.00078$, iNOS: $0.00141 \pm 0.00034$ mRNA / PPIA). Expression of IL6 was reduced by candesartan treatment in control antibody treated mice $(p<0.05 ;$ Fig. 3D). There was a tendency towards lower IL6 expression in vehicle treated ND-mice compared to vehicle treated Ctrl-mice $(p=0.09$; Fig. 3D). There was a strong tendency towards lower IL1 $\beta$ expression in candesartan treated Ctrl-mice compared to vehicle treated Ctrl-mice ( $p=0.06$; Fig. 3E). TGF $\beta$ was elevated in ND-mice by candesartan as well as in Cand-mice by anti-Ly6G-treatment. Gene expressions of TNFa and iNOS were not affected by any treatment.

\subsection{4: Neutrophil depletion and AT1 inhibition had no effect on neurological outcome}

Neurological assessment was performed 1 day before, and 24 and 72 hours after TBI using a mNSS and time spent staying on the rotarod. Compared to pre-trauma values, $\mathrm{CCl}$ induced a highly significant impairment in all experimental groups 24 hours after TBI in mNSS ( $p<0.001$; Fig. 3F). Time spent on the rotarod and mNSS improved over time 3 days after TBI without differences between the treatment groups.

\subsection{Study D: Effect of RAG1 deficiency and AT1 inhibition}




\subsubsection{AT1 inhibition reduced lesion volume in RAG1- deficient mice.}

Three days after TBI in RAG1//- mice lesion volume was reduced by AT1 inhibition from $32.2 \pm 4.6 \mathrm{~mm}^{3}$ (vehicle; $20.3 \pm 2.7 \%$-clh) to $26.8 \pm 4.2 \mathrm{~mm}^{3}$ (candesartan; $17.0 \pm 2.2 \%$-clh; $p<0.05$; Fig. $4 \mathrm{~A}$ ).

\subsubsection{AT1 inhibition reduced cerebral inflammation in RAG1- deficient mice}

Three days after TBI AT1 inhibition reduced activated microglial cells in the cortical region of interest $\left(0.52 \times 0.65 \mathrm{~mm}^{2}\right)$ adjacent to the lesion, from $290 \pm 24\left(\mathrm{n} / \mathrm{mm}^{2}\right.$, vehicle treatment) to $259 \pm 22$ (n / $\mathrm{mm}^{2}$, candesartan treated mice; ${ }^{*} \mathrm{p}<0.05$; Fig. 4B). Additionally, gene expressions were assessed by realtime qPCR, normalized with PPIA and expressed as \% naïve expression (IL1 $\beta$ : $0.00193 \pm 0.00046$, IL6: $0.06207 \pm 0.01296$, TNFa: $1.9017 \pm 0.5769 \times 10^{-6}$, TGF $3: 0.00534 \pm 0.00073$, iNOS: $0.00192 \pm 0.00045$ mRNA / PPIA). Expression of TGF $\beta$ was higher in candesartan treated compared to vehicle treated RAG1 ${ }^{-/-}$mice (Fig. 4C). However, at this time point inflammatory cytokine expression was not affected significantly by AT1 inhibition.

\subsubsection{AT1 inhibition did not affect neurological outcome in RAG1-deficient mice}

Neurological outcome was assessed by mNSS and rotarod at day 1 and 3 after TBI. There was a significant increase of neurological impairment $(p<0.001)$. However neurological deficit was not affected by candesartan treatment (Fig. 4D).

\section{Discussion}

The purpose of the present study was to explore the so far unexplained role of the innate and of the adaptive cellular immune response in the context of AT1 inhibition after TBI. This study investigated for the first time the effect of candesartan treatment in neutrophil depleted as well as in $\mathrm{RAG}^{-/-}$mice. The results suggest that one possible neuroprotective mechanism of AT1 inhibition may be mediated by neutrophils. Initially, the roles of neutrophils and lymphocytes in the development of secondary brain damage after TBI were analyzed. To this end, we successfully achieved sustained neutrophil depletion by treatment with the specific anti-Ly6G antibody. Furthermore, RAG1 deficiency, that results in a lack of mature B- and T-cells, showed significant lymphopenia. The present data show, that reduction of immune cells of the innate and of the adaptive immune system, neutropenia and lymphopenia, each independently lead to reduced brain damage after TBI. Furthermore, the present results demonstrate that posttraumatic AT1 inhibition reduces histological brain damage and limits immune response in control antibody treated mice with normal neutrophil count and in lymphopenic RAG1-deficient mice. In neutrophil depleted mice, however, AT1 inhibition had no effect on brain damage and neuroinflammation. 


\subsection{Experimental setting and blood cell count}

The aim of the present study was to investigate the neuroprotective mechanisms that is mediated by AT1 inhibition and the effects of neutropenia and lymphopenia. To this end we performed the experiments with our established $\mathrm{CCl}$ model $(4,6,8,29,33,34)$. The perioperative setting and the conditions are standardized and physiological values, perioperative temperature and blood pressure showed to be stable (6). For the depletion of neutrophils the novel selective antibody against Ly6G (clone 1A8) was chosen, in order to selectively and significantly reduce the number of neutrophils without affecting other cell types (35-37). In contrast, the widely used less specific antibody for experimental neutrophil depletion anti-Gr1 (clone RB6-8C5) not only reduces Ly6G-specific cells (neutrophils, Gr1+/Ly6G+), but also decreases the number of other lines of WBC with Ly6-receptors (dendritic cells and subpopulations of monocytes and CD8 T-lymphocytes) $(35,38)$. Therefore, in the present study a sustained selective neutrophil depletion during the whole observation period after TBI was successfully achieved by repetitive application of the specific monoclonal antibody anti-Ly6G, with a dosage, based on recent studies $(36,39,40)$. For the assessment of the effects of lymphopenia in TBI the well-established method with RAG1-deficient mice was chosen $(41,42)$. Activated RAG1 plays a key role in VDJ-recombination. RAG1 ${ }^{-/-}$have small lymphatic organs without mature B- and T-lymphocytes (43) and in the present study they showed to have a significant lymphopenia. The observation times of each study were chosen with respect to the maximum brain tissue infiltration of the two immune cell types. After an early posttraumatic liberation of neutrophils from bone marrow and other reservoirs (44) neutrophils are the dominant blood cell population 24 hours after TBI (45). They infiltrate early after TBI into hippocampal and cortical brain tissue (between 4 and 72 hours) and reach a maximum of parenchymal infiltration at 1 day after TBI (46, 47). Therefore, in study A we applied the observation time lengths of 4 and 24 hours post CCl.

Lymphocytes invade into cerebral tissue from the third day on after injury $(6,46)$. In study $B$, therefore, we chose the observation time lengths of 1 and 5 days after TBI. To facilitate comparability of the effect of candesartan between neutropenic and lymphopenic mice, we decided to use the observation time length of 72 hours after TBI in studies $C$ and D, respectively (46). In order to ensure timely accurate hematologic analyses and interpretation and to minimize pre-analytic errors a mouse-species-appropriate practical hematologic instrumentation was performed with consistent collection method and appropriate anticoagulation (EDTA) (48). The retroorbital sinus as site of blood withdrawal corresponds more with central blood samples than other peripheral sites (49). The present blood cell count results are consistent with recent data (48). The quality can be considered adequate, as the platelet counts are at normal murine levels and cell clumping occurred rarely (48). Within the first hours after TBI, there was a reduction of WBC. Due to trauma-associated neutrophil sequestration, a transient leukopenia is part of the inflammatory reaction after TBI (50). In control antibody (IgG2a) treated mice WBC count normalized one day after TBI. In anti-Ly6G treated mice the initial decrease of WBC was more distinct and sustaining with lasting relatively low WBC to day 3 after TBI. However, at each time point, WBC counts were within physiological range (48). In naïve wild type mice lymphocytes are the predominant leukocytes (70 - $80 \%$ of WBC). Neutrophils are the most common granulocytes in naïve mice and generally comprise $20-30 \%$ of WBC count in mice (48). After TBI neutrophils are the most abundant cell population in circulation and 
cause increased expression of oxidative enzymes (44). In the present study, in Ctrl mice, as a response to $\mathrm{TBI}$, there was a shift from lymphocyte dominated WBC to a significant and sustaining elevation of the neutrophil fraction $(44,45)$. In ND mice, in contrast, instead of a posttraumatic increase of neutrophils, there was neutropenia. From 24 hours on after TBI, the fraction of neutrophils was lower in ND mice than in naïve mice, alongside reduced absolute WBC numbers and a compensatory elevation of lymphocytes. After TBI monocyte counts decreased in all groups, without affection by the selective anti-Ly6G. RAG1 ${ }^{-/-}$ mice showed to be leukopenic and lymphopenia is compensated by elevated neutrophils. In all groups a short-term elevation of hemoglobin and hematocrit in the first hours after TBI, due to pre-traumatic fasting, were normalized in the following observation periods. Platelets were within physiological range in all groups at all time points without affection by treatment. AT1 inhibition had no effect on posttraumatic blood cell count in wild type, neutropenic and $\mathrm{RAG}^{-/-}$mice. In the present study the selective AT1 blocker candesartan was chosen, that crosses the BBB (16). Previous TBI studies demonstrated that

neuroprotection and brain damage reduction were achieved at low doses of candesartan that did not affect blood pressure (8), as a decline in blood pressure immediately after TBI may worsen outcome (51). Furthermore, clinical studies showed beneficial effects of candesartan, independent of the blood pressure lowering effect (52). Therefore, in the present study low dose candesartan $(0.1 \mathrm{mg} / \mathrm{kg})$ was applied that has been shown not to affect blood pressure previously $(4,8,12,17)$. In order to achieve a sustaining AT1 inhibition, treatment was started 30 minutes after TBI and then repeated daily (8). As a result, in the present study, during the whole observation time, posttraumatic blood pressure was not affected by candesartan. The peritraumatic body weight was assessed as a surrogate parameter of well-being and intake of food and water. Neither neutrophil depletion, nor candesartan treatment, had any effect on postoperative body weight loss, that had a maximum on day 2, with recovery on days 3 and 5 .

\subsection{Depletion of neutrophils and lymphopenia lead to reduced brain damage and inflammation}

Neutrophils are an abundant proinflammatory population of circulating leukocytes that are usually among the first responders to tissue injuries in the periphery and the central nervous system (53). After trauma neutrophil sequestration plays a major role in multiple organ failure (50). In the early phase after $\mathrm{TBI}$, neutrophils are the dominating immune cells that infiltrate damaged brain tissue (47), causing an increase of brain damage (46). Evidence suggests that depletion of neutrophils may have beneficial effects in the early phase after TBI. Recent studies have revealed that depletion of neutrophils with antiGr-1 antibodies reduced neuroinflammation and brain tissue loss up to seven days after TBI (54). Actually, in the present study, neutrophil depletion reduced brain damage 24 hours after TBI compared to control group. Alongside the damage reduction, there was a reduction of inflammatory TNFa levels.

Although T cells play diverse roles in adaptive immune responses and the regulation of inflammation, their role in TBI pathogenesis is unresolved (55). Our recent data indicated that cerebral T cell infiltration aggravated neuroinflammation but did not increase lesion volume after TBI $(56,57)$. In a previous closedhead injury study no difference in any pathologic or neurologic parameters was observed between wildtype and RAG $1^{-/-}$mice up to 7 days after closed head injury (41). The authors concluded, that adaptive 
immunity is not of crucial importance for initiating and sustaining inflammatory neuropathology after closed head injury (41). In another TBI (aseptic cerebral injury) study, however, Fee and colleagues demonstrated that $\mathrm{CD} 4^{+} \mathrm{T}$ lymphocytes contribute to the severity of the acute phase of $\mathrm{TBI}$ and that brain injury is attenuated in RAG1 ${ }^{-/-}$mice compared to wild type animals (42). In accordance with these results, in the present study, RAG1 deficiency lead to reduced lesion volumes and neuroinflammation 1 and 5 days after TBI.

However, 24 hours after TBI, neutrophil depletion showed to be more effective in reduction of lesion volume (33\% compared to non-depleted wild type) than lymphopenia (17\% compared to wild type). It has been shown that acute posttraumatic cerebral infiltration of neutrophils is more distinct, compared to infiltration of lymphocytes (46). Therefore, it is possible that a reduction of neutrophil infiltration may have a stronger anti-inflammatory effect in the first days after TBI, than a reduction of lymphocyte infiltration. This may explain why in studies with neutrophil depletion brain damage and inflammation are consistently reduced (54) and why in studies with RAG1 deficiency the results are inconsistent $(41,42$, 56).

\subsection{AT1 inhibition reduced histological brain damage and microglial activation in non-neutrophil depleted mice and RAG1 deficient mice, whereas candesartan treatment failed to be neuroprotective in neutrophil depleted mice}

Growing amount of evidence shows that the entire cellular immune response (granulocytes, monocytes, lymphocytes, etc.) is modulated by the RAS $(58,59)$. Angiotensin II, via AT1 is one of the most important inducers and perpetuators of cerebral inflammation and oxidative stress $(7,60)$. AT1 is widely expressed in the mature central nervous system, mainly in neurons, endothelial and smooth muscle cells, astrocytes and microglia, important modulators of neuroinflammation $(9,61)$. AT1 is also expressed on migrating immune cells, like neutrophils, macrophages and T-cells. AT1 activation initiates subsequent production of chemokines, cytokines, and adhesion molecules, which contribute to the immigration of these activated immune cells into the lesion $(7,62-65)$. They induce inflammatory responses and release high levels of ROS by activation of NADPH oxidase. AT1 signaling modulates the NADPH oxidase complex activation and induces transcription of several pro-inflammatory cytokines by activation of NF-KB dependent transcription $(15,66)$. This leads to subsequent stimulation of several different kinases that themselves participate in the propagation of inflammatory responses and apoptotic pathways $(17,67-$ 70).

In accordance with recent studies the present study showed that repeated posttraumatic treatment with the selective AT1 inhibitor candesartan resulted 3 days after TBI in a reduced histological brain damage in mice with normal posttraumatic neutrophil count. AT1 inhibition additionally decreased microglial activation and pro-inflammatory signaling in these mice $(8,12)$. In the present study AT1 blockade 
mediated brain damage reduction was accompanied by a decrease of microglial activation, respectively. Activated microglia were reduced by app. $14 \%$ by candesartan and by app. $7 \%$ by neutrophil depletion compared to vehicle and control antibody treatment. Therefore, earlier findings in candesartan treated mice, where number of neutrophils and activated microglia were reduced 3 days after $\operatorname{TBI}(4,17)$ are confirmed in the present study. The pleiotropic cytokine TNFa is produced in microglia, astrocytes and neurons. It is involved in BBB-dysfunction and transmigration of WBC into brain tissue and induces neuronal loss via microglial activation and phagoptosis of neurons $(2,71-73)$. It has been demonstrated earlier that microglial release of TNFa is reduced by AT1 antagonists $(7,74)$. After an early upregulation in the first 8 hours after TBI (72) TNFa decreases significantly in the following time (75). This kinetic could explain that in the present study there is only a reduction of TNFa 4 hours after TBI in ND mice. One of the most potent key pro-inflammatory cytokines is IL1 $\beta$. It plays a major role in leukocyte adhesion, BBB-dysfunction, brain edema and apoptosis as well as in the induction of other pro-inflammatory cytokines. Clinical studies showed a correlation between increased IL1 $\beta$ levels and elevated ICP with worse prognosis (76). Reduced activity of IL1 $\beta$ showed improved neurological outcomes and reduced infiltration of neutrophils $(72,77-79)$. Cerebral IL1 $\beta$ expression increases in the first hour after TBI and reaches highest levels 12 and 24 hours after experimental TBI, and remains elevated up to 48 hours (80). In the present study there is a strong tendency towards lower IL1 $\beta$ expression in candesartan treated control-antibody mice. However, the lack of effect of RAG1 deficiency or neutropenia on IL $1 \beta$ expression in the present study may be due to low cytokine mRNA levels 3 days after $\mathrm{CCl}$ (15). In a recent study, we could demonstrate reduced cytokine expression by AT1 inhibition 12 hours after TBI (8). Several studies have shown that the cytokine IL6 is up-regulated after TBI with consecutive increased microglia activation and neurological impairment $(2,81)$. Clinical studies postulate a correlation between elevated IL6 serum levels, ICP increase and severity of TBI (82). Furthermore, IL6 regulates migration of neutrophils during acute inflammation (83). In the present study IL6 is reduced by AT1 inhibition three days after TBI in control antibody treated mice, whereas in neutropenic mice, candesartan did not affect IL-6 expression.

In a recent study we could demonstrate that posttraumatic AT1 inhibition improved neurological recovery, reduced histological brain damage and limited immune response in young adult and aged mice. We postulated that the protective effect is attributed to a diminished microglia activation and increased antiinflammatory microglia polarization. One major finding was that neutrophil infiltration was largely reduced (4). As AT1 is expressed on circulating neutrophils and lymphocytes $(64,84)$, several studies indicate that infiltrations of both immune cell types, neutrophils and lymphocytes are reduced by AT1 blockade $(85,86)$. However, in our recent study perilesional T-cell immigration was not affected by AT1 inhibition (4). Neuroprotective mechanisms of AT1 inhibition in the acute phase after TBI may therefore be independent of adaptive lymphocyte reaction. A recent study showed that expression of CD62L on human neutrophils is modulated by AT1 receptors, on pathways involving extracellular signal-regulated kinases 1 and 2 (ERK1/2) mitogen-activated protein kinase (MAPK), phosphatidylinositol 3-kinase, and calcineurin (87), leading to reduced transmigration of neutrophils. Recent studies revealed that AT1 inhibition leads to down regulation of important recruitment proteins like ICAM1 in endothelial cells and 
CD11b/CD18 on WBC and the post traumatic increase of BBB permeability. Consecutively, the infiltration of immune cells is largely reduced by AT1 inhibition $(85,86,88,89)$. A recent murine cerebral transcriptomic analysis after TBI showed strong alterations of gene transcription by candesartan treatment. The authors point to a role for candesartan in altering many different aspects of the response to $\mathrm{TBI}$, particularly those involved with cellular response to stress, extracellular matrix alterations and the innate immune response (90). Therefore, AT1 inhibition may have a direct and modulating antiinflammatory effect on invading neutrophils and resident activated microglia (17). The reduction of the cerebral inflammatory response of the innate immune system with reduced microglial activation as well as decreased infiltration of neutrophils may be a putative protective mechanism of AT1 inhibition mediated anti-inflammation and neuroprotection (4).

\section{Conclusions}

Inflammatory response is believed to play a key role in TBI with detrimental effects on brain damage. In order to prove the hypothesis, that AT1 inhibition may constitute an effective neuroprotective strategy against exacerbated neuroinflammation after TBI by affecting the adaptive and the innate immune system, the present study was performed. For the first time the effects of AT1 inhibition in neutrophil depleted and in $\mathrm{RAG}^{-/-}$mice were investigated. The present data show, that reduction of immune cells of the innate and of the adaptive immune system, neutropenia, by anti-Ly6G treatment, and lymphopenia, in $\mathrm{RAG} 1^{-/-}$mice, each independently lead to reduced brain damage after TBI. Furthermore, the present results demonstrate that posttraumatic AT1 inhibition reduces histological brain damage and limits immune response in control antibody treated mice with normal neutrophil count and in lymphopenic RAG1-deficient mice. AT1 inhibition was highly effective in animals to reduce brain damage by reducing microglial response. In neutrophil depleted mice, however, AT1 blockage had no effect on brain damage and neuroinflammation. We conclude, that protective effects of AT1 inhibition are independent of lymphocytes but dependent on neutrophils. Therefore, AT1 inhibition may exert its neuroprotective properties by affecting neutrophil invasion into injured brain tissue. AT1 inhibition is a promising therapeutic strategy to limit secondary brain damage after TBI. The present data may help to understand the TBI pathophysiology and develop optimal pharmacologic intervention for TBI patients.

\section{Abbreviations}




\begin{tabular}{ll} 
Angll & angiotensin II \\
\hline AT1 & angiotensin II receptor type 1 \\
\hline Cand & candesartan treated mice \\
\hline CCI & controlled cortical impact \\
\hline \%-Clh & percentage of contralateral hemisphere \\
\hline Ctrl & control antibody treated mice (IgG2a) \\
\hline IL1 $\beta$ & interleukin 1 $\beta$ \\
\hline IL6 & interleukin 6 \\
\hline iNOS & inducible nitric oxide synthase \\
\hline ND & neutrophil depleted mice (Ly6G-antibody) \\
\hline PPIA & cyclophilin A \\
\hline qPCR & quantitative polymerase chain reaction \\
\hline RAG1 & recombination activating gene 1 \\
\hline TGF $\beta$ & transforming growth factor $\beta$ \\
\hline TNFa & tumor necrosis factor a \\
\hline TBI & traumatic brain injury \\
\hline Veh & vehicle solution treated mice
\end{tabular}

\section{Declarations}

Ethics approval: The studies were performed with the approval of the Animal Care and Ethics Committee of Rhineland-Palatinate, Germany in accordance with the institutional guidelines of the Johannes Gutenberg University, Mainz (protocol number: 23177-07/G13-1-046).

Consent for publication: Not applicable.

Availability of data and materials: The datasets used and/or analyzed during the current study are available from the corresponding author on reasonable request.

Competing interests: The authors declare that they have no actual or potential competing interests.

Funding: The study was supported by a grant from the University Medical Center of the Johannes Gutenberg University, Mainz, Germany (Stufe 1).

\section{Authors' contributions:}


RTK is the corresponding author. He was the major contributor to study conceptions and acquisition of funding. He planned and designed the studies, performed and supervised the experiments, analyzed and interpreted the data regarding the hematological, histological, molecular biological and neurological assessments. RTK wrote the manuscript. SPCC made substantial contributions in planning and designing the studies, performed the histological and molecular biological examination of the brains, she helped with hematological examinations and prepared the blood cell count. She was a major contributor in writing the manuscript. TK performed experiments, blood withdrawals and histological examinations, he made substantial contributions in data acquisitions. AVH performed experiments and histological examinations, made substantial contributions in data acquisitions. MKS made substantial contributions in data analysis and interpretation regarding molecular biology. AS contributed substantially in data acquisition of histology and molecular biology. SCT was a major contributor in study conception, data interpretation, and writing the manuscript. All authors read and approved the final manuscript.

Acknowledgements: The authors want to thank Prof. Dr. Karl J. Lackner, Dr. Davit Manukyan and all the experimental coworkers of the Institute of Clinical Chemistry and Laboratory Medicine of the University Medical Center of Johannes Gutenberg-University Mainz for providing the hematological data. We also wish to thank Dana Pieter and Tobias Hirnet for their excellent technical assistance.

Additional information: Some of the data in this article are from the doctoral thesis of Shila P. Coronel Castello and the professorial dissertation (Habilitation) of Ralph Timaru-Kast, both presented to the Medical Faculty of the Johannes Gutenberg University, Mainz, Germany.

\section{References}

1. Langlois JA, Rutland-Brown W, Wald MM. The epidemiology and impact of traumatic brain injury: a brief overview. JHead Trauma Rehabil. 2006;21(5):375-8.

2. Morganti-Kossmann MC, Rancan M, Otto VI, Stahel PF, Kossmann T. Role of cerebral inflammation after traumatic brain injury: a revisited concept. Shock. 2001;16(3):165-77.

3. Kelso ML, Gendelman HE. Bridge between neuroimmunity and traumatic brain injury. Curr Pharm Design. 2014;20(26):4284-98.

4. Timaru-Kast R, Gotthardt P, Luh C, Huang C, Hummel R, Schafer MKE, et al. Angiotensin II Receptor 1 Blockage Limits Brain Damage and Improves Functional Outcome After Brain Injury in Aged Animals Despite Age-Dependent Reduction in AT1 Expression. Front Aging Neurosci. 2019;11:63.

5. Smith C, Gentleman SM, Leclercq PD, Murray LS, Griffin WS, Graham DI, et al. The neuroinflammatory response in humans after traumatic brain injury. Neuropathol Appl Neurobiol. 2013;39(6):654-66.

6. Timaru-Kast R, Luh C, Gotthardt P, Huang C, Schafer MK, Engelhard K, et al. Influence of age on brain edema formation, secondary brain damage and inflammatory response after brain trauma in mice. PloS one. 2012;7(8):e43829.

7. Villar-Cheda B, Dominguez-Meijide A, Valenzuela R, Granado N, Moratalla R, Labandeira-Garcia JL. Aging-related dysregulation of dopamine and angiotensin receptor interaction. Neurobiol Aging. 
2014;35(7):1726-38.

8. Timaru-Kast R, Wyschkon S, Luh C, Schaible EV, Lehmann F, Merk P, et al. Delayed inhibition of angiotensin II receptor type 1 reduces secondary brain damage and improves functional recovery after experimental brain trauma*. Critical care medicine. 2012;40(3):935-44.

9. Saavedra JM. Brain angiotensin II: new developments, unanswered questions and therapeutic opportunities. Cell MolNeurobiol. 2005;25(3-4):485-512.

10. Saavedra JM. Angiotensin II AT(1) receptor blockers ameliorate inflammatory stress: a beneficial effect for the treatment of brain disorders. Cell Mol Neurobiol. 2012;32(5):667-81.

11. Saavedra JM, Ando H, Armando I, Baiardi G, Bregonzio C, Jezova M, et al. Brain angiotensin II, an important stress hormone: regulatory sites and therapeutic opportunities. AnnNYAcadSci. 2004;1018:76-84.

12. Villapol S, Yaszemski AK, Logan TT, Sanchez-Lemus E, Saavedra JM, Symes AJ. Candesartan, an angiotensin II AT(1)-receptor blocker and PPAR-gamma agonist, reduces lesion volume and improves motor and memory function after traumatic brain injury in mice. Neuropsychopharmacology: official publication of the American College of Neuropsychopharmacology. 2012;37(13):2817-29.

13. Culman J, Blume A, Gohlke P, Unger T. The renin-angiotensin system in the brain: possible therapeutic implications for AT(1)-receptor blockers. JHumHypertens. 2002;16(Suppl 3):64-70.

14. Rey P, Lopez-Real A, Sanchez-Iglesias S, Munoz A, Soto-Otero R, Labandeira-Garcia JL. Angiotensin type-1-receptor antagonists reduce 6-hydroxydopamine toxicity for dopaminergic neurons. Neurobiol Aging. 2007;28(4):555-67.

15. Borrajo A, Rodriguez-Perez Al, Villar-Cheda B, Guerra MJ, Labandeira-Garcia JL. Inhibition of the microglial response is essential for the neuroprotective effects of Rho-kinase inhibitors on MPTPinduced dopaminergic cell death. Neuropharmacology. 2014;85:1-8.

16. Villapol S, Saavedra JM. Neuroprotective effects of angiotensin receptor blockers. Am J Hypertens. 2015;28(3):289-99.

17. Villapol S, Balarezo MG, Affram K, Saavedra JM, Symes AJ. Neurorestoration after traumatic brain injury through angiotensin II receptor blockage. Brain: a journal of neurology. 2015.

18. Thal SC, Plesnila N. Non-invasive intraoperative monitoring of blood pressure and arterial pCO(2) during surgical anesthesia in mice. JNeurosciMethods. 2007;159(2):261-7.

19. Thal SC, Heinemann M, Luh C, Pieter D, Werner C, Engelhard K. Pioglitazone reduces secondary brain damage after experimental brain trauma by PPAR-gamma-independent mechanisms. JNeurotrauma. 2011;28(6):983-93.

20. Deacon RM. Measuring motor coordination in mice. J Vis Exp. 2013(75):e2609.

21. Hamm RJ. Neurobehavioral assessment of outcome following traumatic brain injury in rats: an evaluation of selected measures. J Neurotrauma. 2001;18(11):1207-16.

22. Pottker B, Stober F, Hummel R, Angenstein F, Radyushkin K, Goldschmidt J, et al. Traumatic brain injury causes long-term behavioral changes related to region-specific increases of cerebral blood 
flow. Brain structure function. 2017;222(9):4005-21.

23. Sebastiani A, Golz C, Werner C, Schafer MK, Engelhard K, Thal SC. Proneurotrophin Binding to P75 Neurotrophin Receptor (P75ntr) Is Essential for Brain Lesion Formation and Functional Impairment after Experimental Traumatic Brain Injury. J Neurotrauma. 2015;32(20):1599-607.

24. Tsenter J, Beni-Adani L, Assaf Y, Alexandrovich AG, Trembovler V, Shohami E. Dynamic changes in the recovery after traumatic brain injury in mice: effect of injury severity on T2-weighted MRI abnormalities, and motor and cognitive functions. JNeurotrauma. 2008;25(4):324-33.

25. Huang C, Sakry D, Menzel L, Dangel L, Sebastiani A, Kramer T, et al. Lack of NG2 exacerbates neurological outcome and modulates glial responses after traumatic brain injury. Glia. 2016;64(4):507-23.

26. Sharma A, Fish BL, Moulder JE, Medhora M, Baker JE, Mader M, et al. Safety and blood sample volume and quality of a refined retro-orbital bleeding technique in rats using a lateral approach. Lab Anim (NY). 2014;43(2):63-6.

27. Donat CK, Scott G, Gentleman SM, Sastre M. Microglial Activation in Traumatic Brain Injury. Front Aging Neurosci. 2017;9:208.

28. Luh C, Kuhlmann CR, Ackermann B, Timaru-Kast R, Luhmann HJ, Behl C, et al. Inhibition of myosin light chain kinase reduces brain edema formation after traumatic brain injury. Journal of neurochemistry. 2010;112(4):1015-25.

29. Timaru-Kast R, Herbig EL, Luh C, Engelhard K, Thal SC. Influence of age on cerebral housekeeping gene expression for normalization of quantitative PCR after acute brain injury in mice. Journal of neurotrauma. 2015.

30. Thal SC, Wyschkon S, Pieter D, Engelhard K, Werner C. Selection of endogenous control genes for normalization of gene expression analysis after experimental brain trauma in mice. JNeurotrauma. 2008;25(7):785-94.

31. Garcia-Bardon A, Thal SC. Normalization with Corresponding Naive Tissue Minimizes Bias Caused by Commercial Reverse Transcription Kits on Quantitative Real-Time PCR Results. PloS one. 2016;11(11):e0167209.

32. Faul F, Erdfelder E, Buchner A, Lang AG. Statistical power analyses using G*Power 3.1: tests for correlation and regression analyses. Behav Res Methods. 2009;41(4):1149-60.

33. Thal SC, Schaible EV, Neuhaus W, Scheffer D, Brandstetter M, Engelhard K, et al. Inhibition of proteasomal glucocorticoid receptor degradation restores dexamethasone-mediated stabilization of the blood-brain barrier after traumatic brain injury. Critical care medicine. 2013;41(5):1305-15.

34. Sebastiani A, Granold M, Ditter A, Sebastiani P, Golz C, Pottker B, et al. Posttraumatic Propofol Neurotoxicity Is Mediated via the Pro-Brain-Derived Neurotrophic Factor-p75 Neurotrophin Receptor Pathway in Adult Mice. Critical care medicine. 2016;44(2):e70-82.

35. Daley JM, Thomay AA, Connolly MD, Reichner JS, Albina JE. Use of Ly6G-specific monoclonal antibody to deplete neutrophils in mice. J Leukoc Biol. 2008;83(1):64-70. 
36. Carr KD, Sieve AN, Indramohan M, Break TJ, Lee S, Berg RE. Specific depletion reveals a novel role for neutrophil-mediated protection in the liver during Listeria monocytogenes infection. Eur J Immunol. 2011;41(9):2666-76.

37. Yipp BG, Kubes P. Antibodies against neutrophil LY6G do not inhibit leukocyte recruitment in mice in vivo. Blood. 2013;121(1):241-2.

38. Wojtasiak M, Pickett DL, Tate MD, Londrigan SL, Bedoui S, Brooks AG, et al. Depletion of Gr-1+, but not Ly6G+, immune cells exacerbates virus replication and disease in an intranasal model of herpes simplex virus type 1 infection. J Gen Virol. 2010;91(Pt 9):2158-66.

39. Bamboat ZM, Ocuin LM, Balachandran VP, Obaid H, Plitas G, DeMatteo RP. Conventional DCs reduce liver ischemia/reperfusion injury in mice via IL-10 secretion. J Clin Investig. 2010;120(2):559-69.

40. Ocuin LM, Bamboat ZM, Balachandran VP, Cavnar MJ, Obaid H, Plitas G, et al. Neutrophil IL-10 suppresses peritoneal inflammatory monocytes during polymicrobial sepsis. J Leukoc Biol. 2011;89(3):423-32.

41. Weckbach S, Neher M, Losacco JT, Bolden AL, Kulik L, Flierl MA, et al. Challenging the role of adaptive immunity in neurotrauma: Rag1(-/-) mice lacking mature $B$ and $T$ cells do not show neuroprotection after closed head injury. J Neurotrauma. 2012;29(6):1233-42.

42. Fee D, Crumbaugh A, Jacques T, Herdrich B, Sewell D, Auerbach D, et al. Activated/effector CD4+ T cells exacerbate acute damage in the central nervous system following traumatic injury. $\mathrm{J}$ Neuroimmunol. 2003;136(1-2):54-66.

43. Mombaerts P, lacomini J, Johnson RS, Herrup K, Tonegawa S, Papaioannou VE. RAG-1-deficient mice have no mature B and T lymphocytes. Cell. 1992;68(5):869-77.

44. Liao Y, Liu P, Guo F, Zhang ZY, Zhang Z. Oxidative burst of circulating neutrophils following traumatic brain injury in human. PloS one. 2013;8(7):e68963.

45. Simon DW, McGeachy MJ, Bayir H, Clark RS, Loane DJ, Kochanek PM. The far-reaching scope of neuroinflammation after traumatic brain injury. Nat Rev Neurol. 2017;13(3):171-91.

46. Jin X, Ishii H, Bai Z, Itokazu T, Yamashita T. Temporal changes in cell marker expression and cellular infiltration in a controlled cortical impact model in adult male C57BL/6 mice. PloS one. 2012;7(7):e41892.

47. Royo NC, Wahl F, Stutzmann JM. Kinetics of polymorphonuclear neutrophil infiltration after a traumatic brain injury in rat. Neuroreport. 1999;10(6):1363-7.

48. O'Connell KE, Mikkola AM, Stepanek AM, Vernet A, Hall CD, Sun CC, et al. Practical murine hematopathology: a comparative review and implications for research. Comp Med. 2015;65(2):96113.

49. Nemzek JA, Bolgos GL, Williams BA, Remick DG. Differences in normal values for murine white blood cell counts and other hematological parameters based on sampling site. Inflammation research: official journal of the European Histamine Research Society [et al]. 2001;50(10):523-7.

50. Botha AJ, Moore FA, Moore EE, Sauaia A, Banerjee A, Peterson VM. Early neutrophil sequestration after injury: a pathogenic mechanism for multiple organ failure. J Trauma. 1995;39(3):411-7. 
51. Andriessen TM, Jacobs B, Vos PE. Clinical characteristics and pathophysiological mechanisms of focal and diffuse traumatic brain injury. J Cell Mol Med. 2010;14(10):2381-92.

52. Hajjar I, Okafor M, McDaniel D, Obideen M, Dee E, Shokouhi M, et al. Effects of Candesartan vs Lisinopril on Neurocognitive Function in Older Adults With Executive Mild Cognitive Impairment: A Randomized Clinical Trial. JAMA Netw Open. 2020;3(8):e2012252.

53. Kolaczkowska E, Kubes P. Neutrophil recruitment and function in health and inflammation. Nature reviews Immunology. 2013;13(3):159-75.

54. Kenne E, Erlandsson A, Lindbom L, Hillered L, Clausen F. Neutrophil depletion reduces edema formation and tissue loss following traumatic brain injury in mice. J Neuroinflamm. 2012;9:17.

55. Corps KN, Roth TL, McGavern DB. Inflammation and neuroprotection in traumatic brain injury. JAMA Neurol. 2015;72(3):355-62.

56. Kramer TJ, Hack N, Bruhl TJ, Menzel L, Hummel R, Griemert EV, et al. Correction to: Depletion of regulatory $T$ cells increases $T$ cell brain infiltration, reactive astrogliosis, and interferon-gamma gene expression in acute experimental traumatic brain injury. J Neuroinflamm. 2019;16(1):176.

57. Kramer TJ, Hack N, Bruhl TJ, Menzel L, Hummel R, Griemert EV, et al. Depletion of regulatory T cells increases $T$ cell brain infiltration, reactive astrogliosis, and interferon-gamma gene expression in acute experimental traumatic brain injury. J Neuroinflamm. 2019;16(1):163.

58. Okamura A, Rakugi H, Ohishi M, Yanagitani Y, Takiuchi S, Moriguchi K, et al. Upregulation of reninangiotensin system during differentiation of monocytes to macrophages. Journal of hypertension. 1999;17(4):537-45.

59. Kossmann S, Schwenk M, Hausding M, Karbach SH, Schmidgen MI, Brandt M, et al. Angiotensin IIinduced vascular dysfunction depends on interferon-gamma-driven immune cell recruitment and mutual activation of monocytes and NK-cells. Arteriosclerosis, thrombosis, and vascular biology. 2013;33(6):1313-9.

60. Ranjbar R, Shafiee M, Hesari A, Ferns GA, Ghasemi F, Avan A. The potential therapeutic use of reninangiotensin system inhibitors in the treatment of inflammatory diseases. Journal of cellular physiology. 2019;234(3):2277-95.

61. Febinger HY, Thomasy HE, Pavlova MN, Ringgold KM, Barf PR, George AM, et al. Time-dependent effects of CX3CR1 in a mouse model of mild traumatic brain injury. J Neuroinflamm. 2015;12:154.

62. Suzuki Y, Ruiz-Ortega M, Lorenzo O, Ruperez M, Esteban V, Egido J. Inflammation and angiotensin II. Int J Biochem Cell Biol. 2003;35(6):881-900.

63. Toth AD, Turu G, Hunyady L, Balla A. Novel mechanisms of G-protein-coupled receptors functions: AT1 angiotensin receptor acts as a signaling hub and focal point of receptor cross-talk. Best Pract Res Clin Endocrinol Metab. 2018;32(2):69-82.

64. Ito $\mathrm{H}$, Takemori K, Suzuki T. Role of angiotensin II type 1 receptor in the leucocytes and endothelial cells of brain microvessels in the pathogenesis of hypertensive cerebral injury. Journal of hypertension. 2001;19(3 Pt 2):591-7. 
65. Guzik TJ, Hoch NE, Brown KA, McCann LA, Rahman A, Dikalov S, et al. Role of the T cell in the genesis of angiotensin II induced hypertension and vascular dysfunction. The Journal of experimental medicine. 2007;204(10):2449-60.

66. Rodriguez-Perez Al, Borrajo A, Rodriguez-Pallares J, Guerra MJ, Labandeira-Garcia JL. Interaction between NADPH-oxidase and Rho-kinase in angiotensin Il-induced microglial activation. Glia. 2015;63(3):466-82.

67. Cherry JD, Olschowka JA, O'Banion MK. Neuroinflammation and M2 microglia: the good, the bad, and the inflamed. J Neuroinflamm. 2014;11:98.

68. Rodriguez-Perez Al, Dominguez-Meijide A, Lanciego JL, Guerra MJ, Labandeira-Garcia JL. Dopaminergic degeneration is enhanced by chronic brain hypoperfusion and inhibited by angiotensin receptor blockage. Age (Dordr). 2013;35(5):1675-90.

69. Labandeira-Garcia JL, Rodriguez-Pallares J, Dominguez-Meijide A, Valenzuela R, Villar-Cheda B, Rodriguez-Perez Al. Dopamine-angiotensin interactions in the basal ganglia and their relevance for Parkinson's disease. Movement disorders: official journal of the Movement Disorder Society. 2013;28(10):1337-42.

70. Villar-Cheda B, Valenzuela R, Rodriguez-Perez Al, Guerra MJ, Labandeira-Garcia JL. Aging-related changes in the nigral angiotensin system enhances proinflammatory and pro-oxidative markers and 6-OHDA-induced dopaminergic degeneration. Neurobiol Aging. 2012;33(1):204 e1-11.

71. Neniskyte U, Vilalta A, Brown GC. Tumour necrosis factor alpha-induced neuronal loss is mediated by microglial phagocytosis. FEBS Lett. 2014;588(17):2952-6.

72. Woodcock T, Morganti-Kossmann MC. The role of markers of inflammation in traumatic brain injury. Front Neurol. 2013;4:18.

73. Scherbel U, Raghupathi R, Nakamura M, Saatman KE, Trojanowski JQ, Neugebauer E, et al. Differential acute and chronic responses of tumor necrosis factor-deficient mice to experimental brain injury. ProcNatlAcadSciUSA. 1999;96(15):8721-6.

74. Labandeira-Garcia JL, Rodriguez-Pallares J, Villar-Cheda B, Rodriguez-Perez Al, Garrido-Gil P, Guerra MJ. Aging, Angiotensin system and dopaminergic degeneration in the substantia nigra. Aging disease. 2011;2(3):257-74.

75. Borrajo A, Rodriguez-Perez Al, Diaz-Ruiz C, Guerra MJ, Labandeira-Garcia JL. Microglial TNF-alpha mediates enhancement of dopaminergic degeneration by brain angiotensin. Glia. 2014;62(1):14557.

76. Hayakata T, Shiozaki T, Tasaki O, Ikegawa H, Inoue Y, Toshiyuki F, et al. Changes in CSF S100B and cytokine concentrations in early-phase severe traumatic brain injury. Shock. 2004;22(2):102-7.

77. Ozen I, Ruscher K, Nilsson R, Flygt J, Clausen F, Marklund N. Interleukin-1 Beta Neutralization Attenuates Traumatic Brain Injury-Induced Microglia Activation and Neuronal Changes in the Globus Pallidus. Int J Mol Sci. 2020;21(2).

78. Clausen F, Hanell A, Israelsson C, Hedin J, Ebendal T, Mir AK, et al. Neutralization of interleukin-1beta reduces cerebral edema and tissue loss and improves late cognitive outcome following traumatic 
brain injury in mice. Eur J Neurosci. 2011;34(1):110-23.

79. Clausen F, Hanell A, Bjork M, Hillered L, Mir AK, Gram H, et al. Neutralization of interleukin-1beta modifies the inflammatory response and improves histological and cognitive outcome following traumatic brain injury in mice. Eur J Neurosci. 2009;30(3):385-96.

80. Lu KT, Wang YW, Yang JT, Yang YL, Chen HI. Effect of interleukin-1 on traumatic brain injury-induced damage to hippocampal neurons. J Neurotrauma. 2005;22(8):885-95.

81. Morganti-Kossmann MC, Rancan M, Stahel PF, Kossmann T. Inflammatory response in acute traumatic brain injury: a double-edged sword. CurrOpinCrit Care. 2002;8(2):101-5.

82. Hergenroeder GW, Moore AN, McCoy JP Jr, Samsel L, Ward NH 3rd, Clifton GL, et al. Serum IL-6: a candidate biomarker for intracranial pressure elevation following isolated traumatic brain injury. $J$ Neuroinflamm. 2010;7:19.

83. Fielding CA, McLoughlin RM, McLeod L, Colmont CS, Najdovska M, Grail D, et al. IL-6 regulates neutrophil trafficking during acute inflammation via STAT3. J Immunol. 2008;181(3):2189-95.

84. Nataraj C, Oliverio MI, Mannon RB, Mannon PJ, Audoly LP, Amuchastegui CS, et al. Angiotensin II regulates cellular immune responses through a calcineurin-dependent pathway. J Clin Investig. 1999;104(12):1693-701.

85. Bregonzio C, Armando I, Ando H, Jezova M, Baiardi G, Saavedra JM. Anti-inflammatory effects of angiotensin II AT1 receptor antagonism prevent stress-induced gastric injury. Am J Physiol Gastrointest Liver Physiol. 2003;285(2):G414-23.

86. Suzuki Y, Gomez-Guerrero C, Shirato I, Lopez-Franco O, Hernandez-Vargas P, Sanjuan G, et al. Susceptibility to $T$ cell-mediated injury in immune complex disease is linked to local activation of renin-angiotensin system: the role of NF-AT pathway. J Immunol. 2002;169(8):4136-46.

87. Vega A, El Bekay R, Chacon P, Ventura I, Monteseirin J. Angiotensin II induces CD62L shedding in human neutrophils. Atherosclerosis. 2010;209(2):344-51.

88. Takemori K, Ito H, Suzuki T. Effects of the AT1 receptor antagonist on adhesion molecule expression in leukocytes and brain microvessels of stroke-prone spontaneously hypertensive rats. AmJHypertens. 2000;13(11):1233-41.

89. Li Z, Cao Y, Li L, Liang Y, Tian X, Mo N, et al. Prophylactic angiotensin type 1 receptor antagonism confers neuroprotection in an aged rat model of postoperative cognitive dysfunction. Biochem Biophys Res Commun. 2014;449(1):74-80.

90. Attilio PJ, Snapper DM, Rusnak M, Isaac A, Soltis AR, Wilkerson MD, et al. Transcriptomic Analysis of Mouse Brain After Traumatic Brain Injury Reveals That the Angiotensin Receptor Blocker Candesartan Acts Through Novel Pathways. Front Neurosci. 2021;15:636259.

\section{Figures}


A)

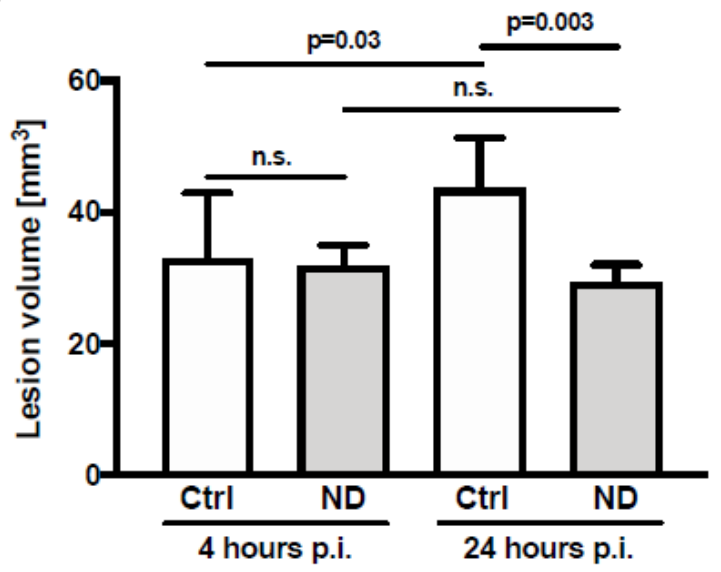

C)

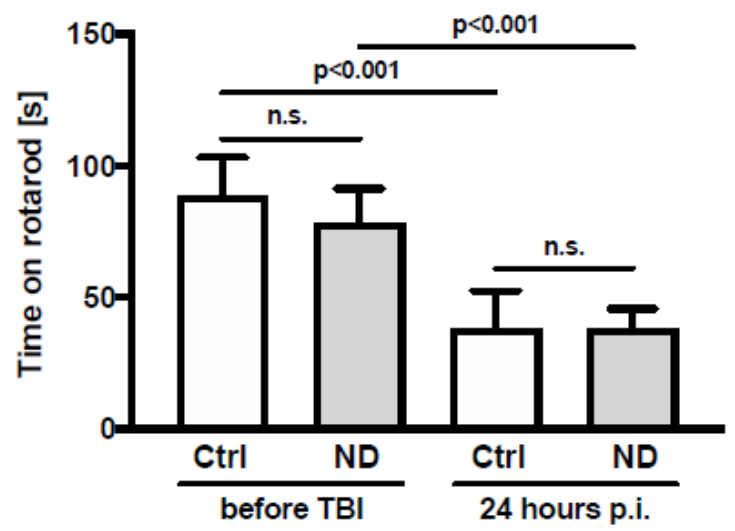

B)

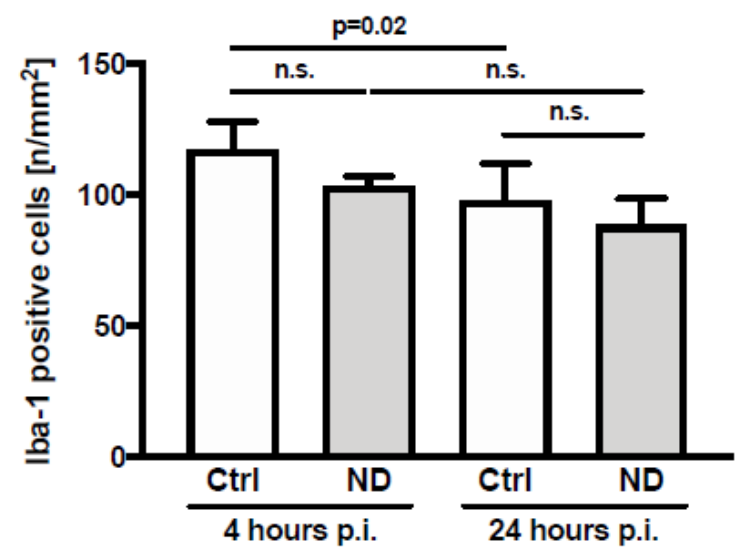

D)

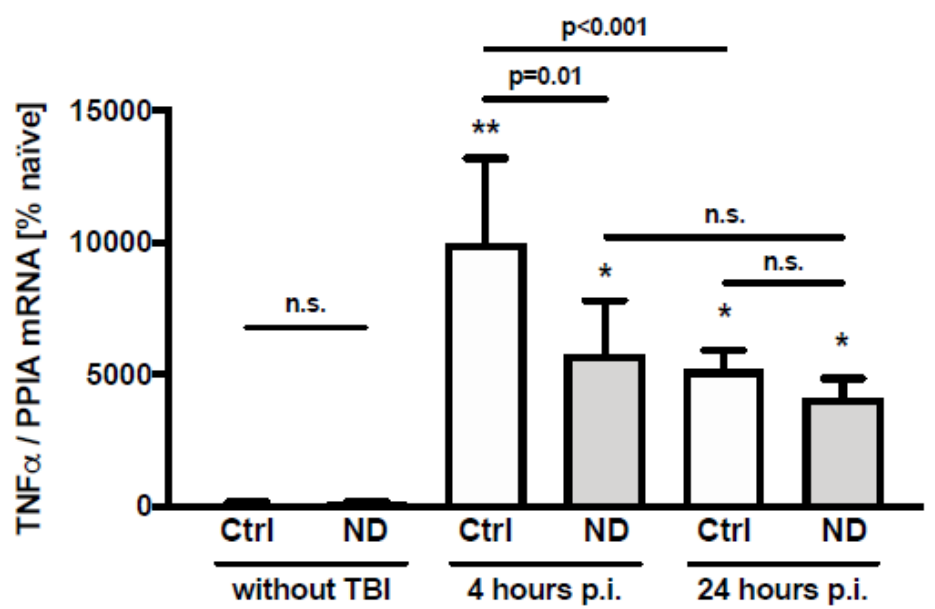

Figure 1

Depletion of neutrophils reduces brain damage after TBI Control antibody IgG2a (2A3) treated groups are depicted in white (Ctrl), neutrophil granulocyte depleted, anti-Ly6G (1A8) treated groups are shown in light grey (ND); 4 hours after TBI: $n=6$ per group, 24 hours after TBI: $n=8$ per group, respectively (p.i. = post injury). A: Lesion volume [mm3] was assessed 4 hours and 24 hours after CCI in Nissl-stained sections: neutrophil depletion reduced lesion volume 24 hours after TBI by $33 \%$. B: Number of activated microglia was as-sessed in cortical perilesional tissue in a ROI $(0.52 \times 0.65 \mathrm{~mm} 2)$ adjacent to the injury (bregma $-1.28 \mathrm{~mm}$ ), expressed as number of Iba-1 positive cells / mm2. C: Neurological outcome was as-sessed before and 24 hours after TBI by time spent on the rotarod [s]. D: Gene expression of TNFa was assessed by real-time qPCR, normalized with PPIA and expressed as \% naïve (normal-ized expression: $2.3488 \pm$ 1.3114 x 10-6 mRNA copies / PPIA). In mice without trauma there was no difference between Ctrl and ND. At 4 hours after TBI Ctrl TNFa expression was significantly higher than ND $\left({ }^{*} p<0.05\right.$ and ${ }^{\star *} p<0.001$ vs. without TBI). A, B, D: Ordinary one-way analysis of variance (ANOVA) with Holm-Šidák's multiple comparisons test. C: Mixed effects analysis (REML) with Holm-Šidák's multiple comparisons test; $p$ < 0.05 ; n.s. = not significant. Data is pre-sented as mean \pm SD. 
A)

24 hours after TBI

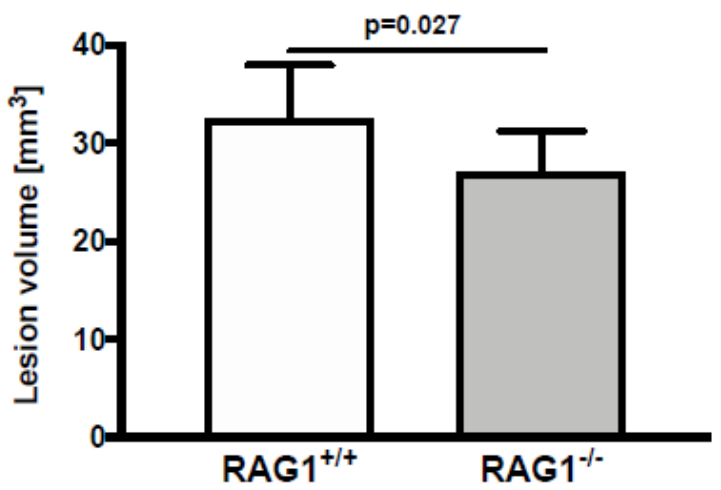

B) 5 days after TBI

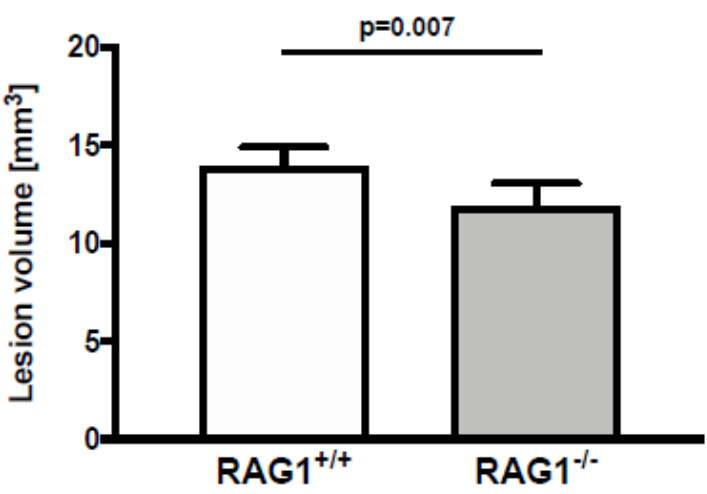

Figure 2

RAG1-deficiency reduced lesion volume compared to wild type mice Lesion volume was assessed in Nissl-stained sections. Wild type mice (RAG1+/+, $\mathrm{n}=10$ ) are shown in white, RAG1-deficient litter mates (RAG1-/-, $\mathrm{n}=10$ ) are depicted in grey. A: 24 hours after TBI in RAG1-/-mice lesion volume was reduced compared to RAG1+/+ mice by $17 \%$. B: Five days after TBI, compared to RAG1+/+ lesion volume was reduced in RAG1-/- by $16 \%$. Unpaired t-test with Welch's correction. Data is presented as mean \pm SD; $p<0.05$.

A)

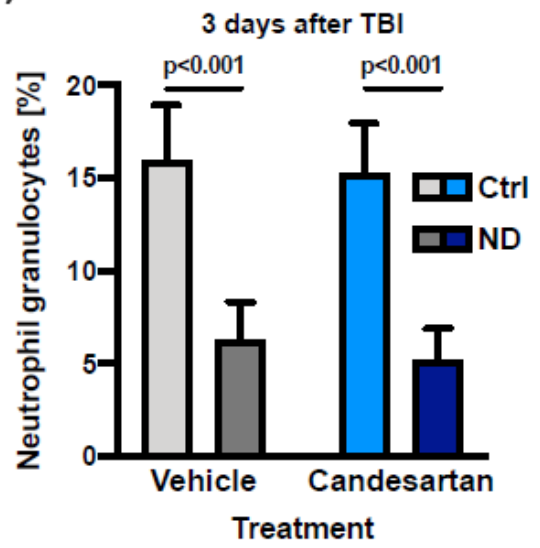

D)

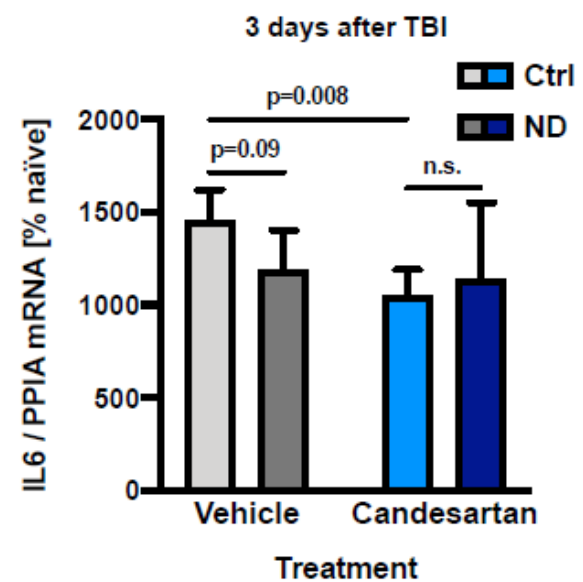

B)

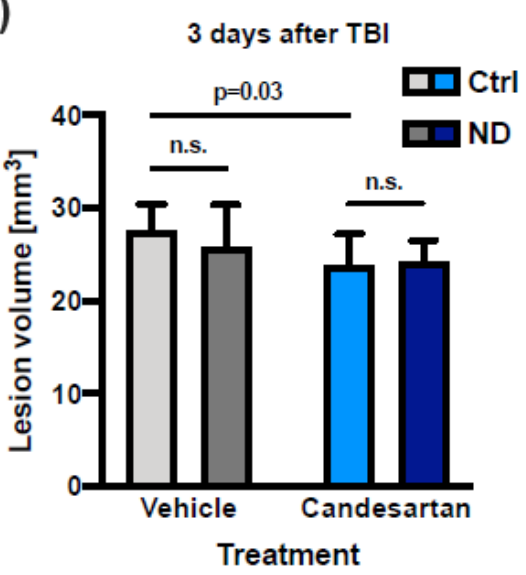

E)

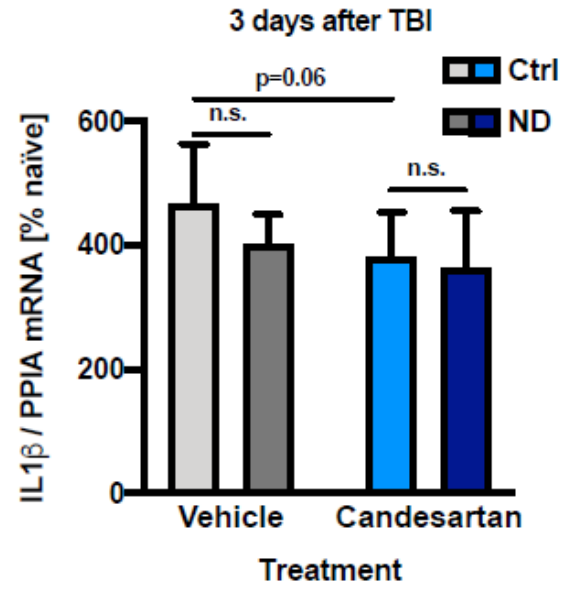

C)

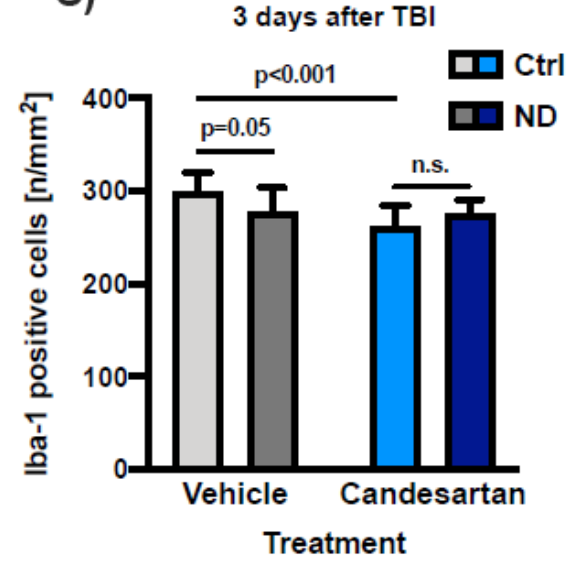

F)

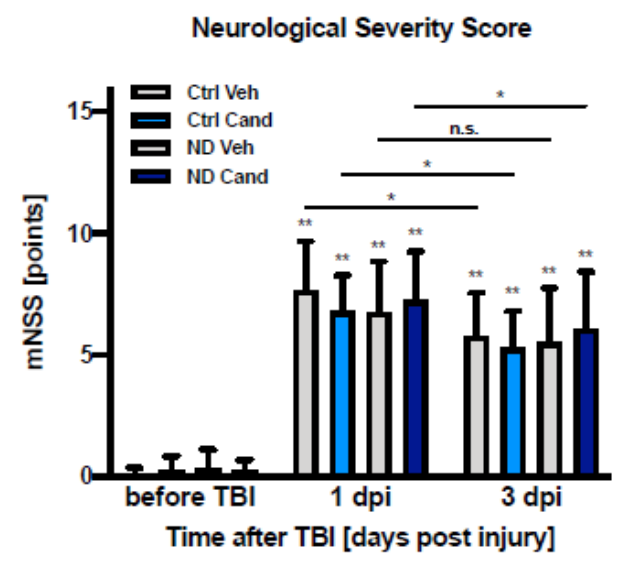




\section{Figure 3}

AT1 inhibition reduced brain damage and inflammation in control antibody treated mice while it had no effect in neutropenic mice. The control antibody IgG2a (2A3) groups are depicted in light colors: vehicle treated mice in sil-ver-grey (Ctrl Veh, $n=12)$, candesartan treated mice in blue (Ctrl Cand, $n=12$ ). The neutrophil granulocyte depleted, anti-Ly6G (1A8) treated groups are shown in dark colors: vehicle treated mice in dark grey (ND Veh, $n=12$ ), candesartan treated mice in dark blue (ND Cand, $n=12$ ). A: Neutrophil granulocyte count [\% WBC]. While anti-Ly6G significantly reduced neutrophils AT1 inhibition did not affect neutrophil count. B: Lesion volume was assessed 72 hours after CCl in Nissl-stained sections. In candesartan and control antibody treated mice lesion volume was significantly reduced compared to vehicle and control antibody treated mice. In anti-Ly6G treated mice AT1 inhibition had no effect on lesion volume. C: Number of activated Iba-1 posi-tive cells as a marker for microglia activation 3 days after TBI, assessed in cortical perilesional tissue in a ROI $(0.52 \times 0.65 \mathrm{~mm} 2$, bregma $-1.28 \mathrm{~mm})$ and expressed as number of activated Iba- 1 positive cells / mm2. In Ctrl-Cand treated mice activated microglia is reduced compared to Ctrl-Veh. D: Gene expression of IL6 (real-time qPCR, normalized with PPIA, expressed as \% naïve (0.06063 \pm 0.01640 mRNA copies / PPIA)): IL6 was reduced by candesartan treatment in control antibody treated mice. E: Gene expression of IL1 $\beta$ (\% naïve $(0.00197 \pm 0.00044$ mRNA copies / PPIA)): There is a strong tendency to lower IL1 $\beta$ expression in Ctrl-Cand compared to CtrlVeh. F: Neurological outcome was assessed 1 day before (before TBI) and 1 and 3 days post injury (dpi) by mNSS ( ${ }^{*} p<0.05 ;{ }^{*} p<0.001$ vs. before TBl; n.s.: not significant). A-E: Two-way analysis of variance (ANOVA) with Holm-Šidák's multiple comparisons test. F: Mixed effects analy-sis (REML) with HolmŠidák's multiple comparisons test. Data is presented as mean $\pm S D ; p<0.05$. 
A)

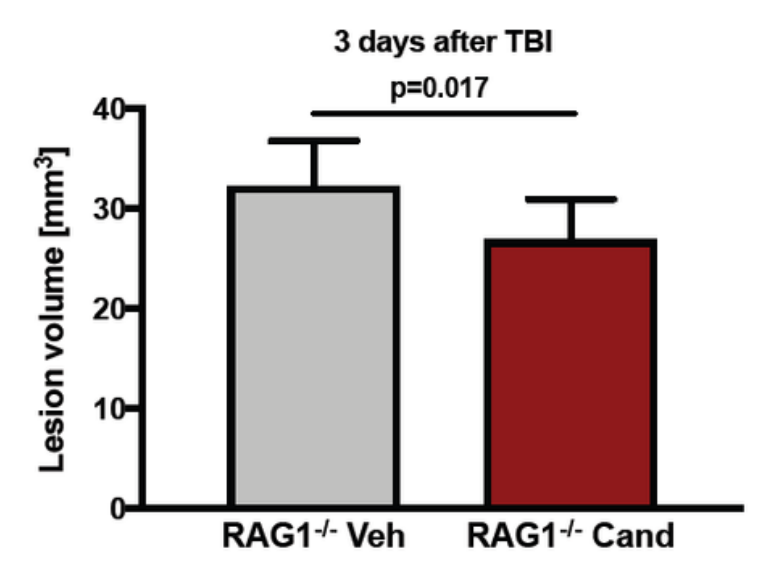

C)

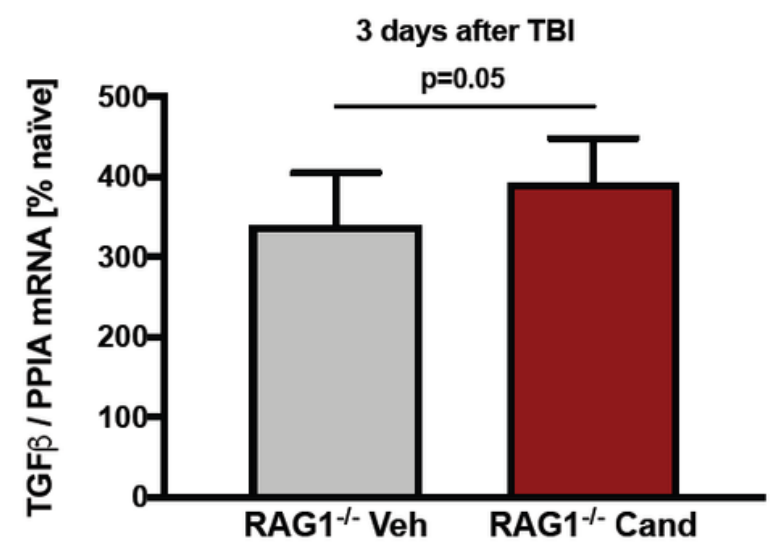

B)

3 days after TBI

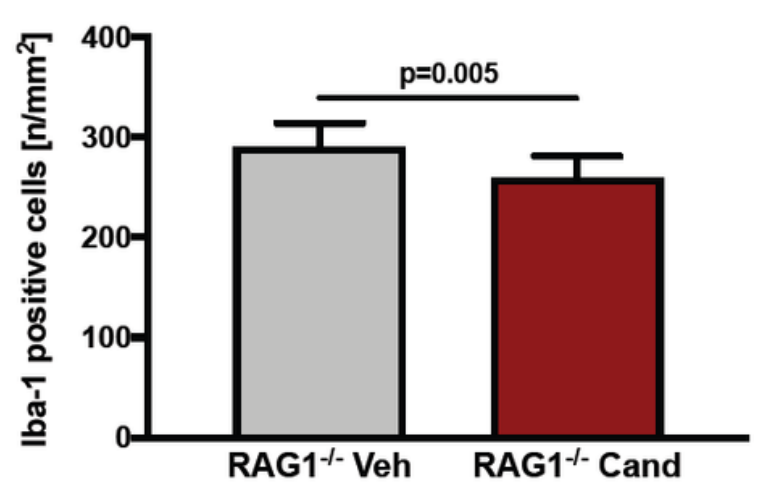

D)

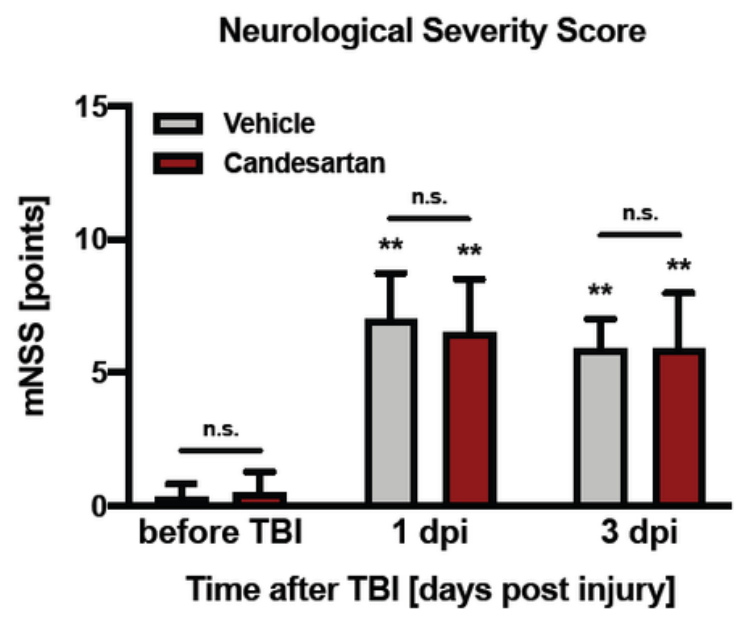

Figure 4

AT1 inhibition reduced brain damage and inflammation in lymphopenic RAG1-deficient mice. Vehicle solution treated RAG1-/-mice (RAG1-/-Veh; $\mathrm{n}=12$ ) are shown in grey, candesartan treated RAG1-/-mice (RAG1-/- Cand; $n=12$ ) are depicted in red. A: Lesion volume was assessed in Nissl stained brain sections three days after TBI. In RAG1-/- Cand lesion volume was reduced compared to RAG1-/-Veh. B: Three days after TBI AT1 inhibition (RAG1-/- Cand) reduced acti-vated microglial Iba1-positive cells in the cortical perilesional region of interest (ROI: $0.52 \times 0.65 \mathrm{~mm} 2$, bregma $-1.28 \mathrm{~mm}$ ) compared to RAG1-/-Veh (expressed as number of activated Iba-1 posi-tive cells / mm2). C: Normalized gene expression of TGF $\beta$ expressed as \% naïve expression (0.00534 \pm 0.00073 mRNA/PPIA; real-time qPCR) was higher in RAG1-/Cand compared to RAG1-/-Veh. D: Neurological outcome was assessed by mNSS at day 1 and 3 after $\mathrm{TBI}$ (dpi = days post injury). A-C: Unpaired t-test with Welch's correction. D: Mixed effects analysis (REML) with Holm-Šidák's multiple com-parisons test. Data is presented as mean $\pm S D ; p<0.05 ; n . s .=$ not significant. 


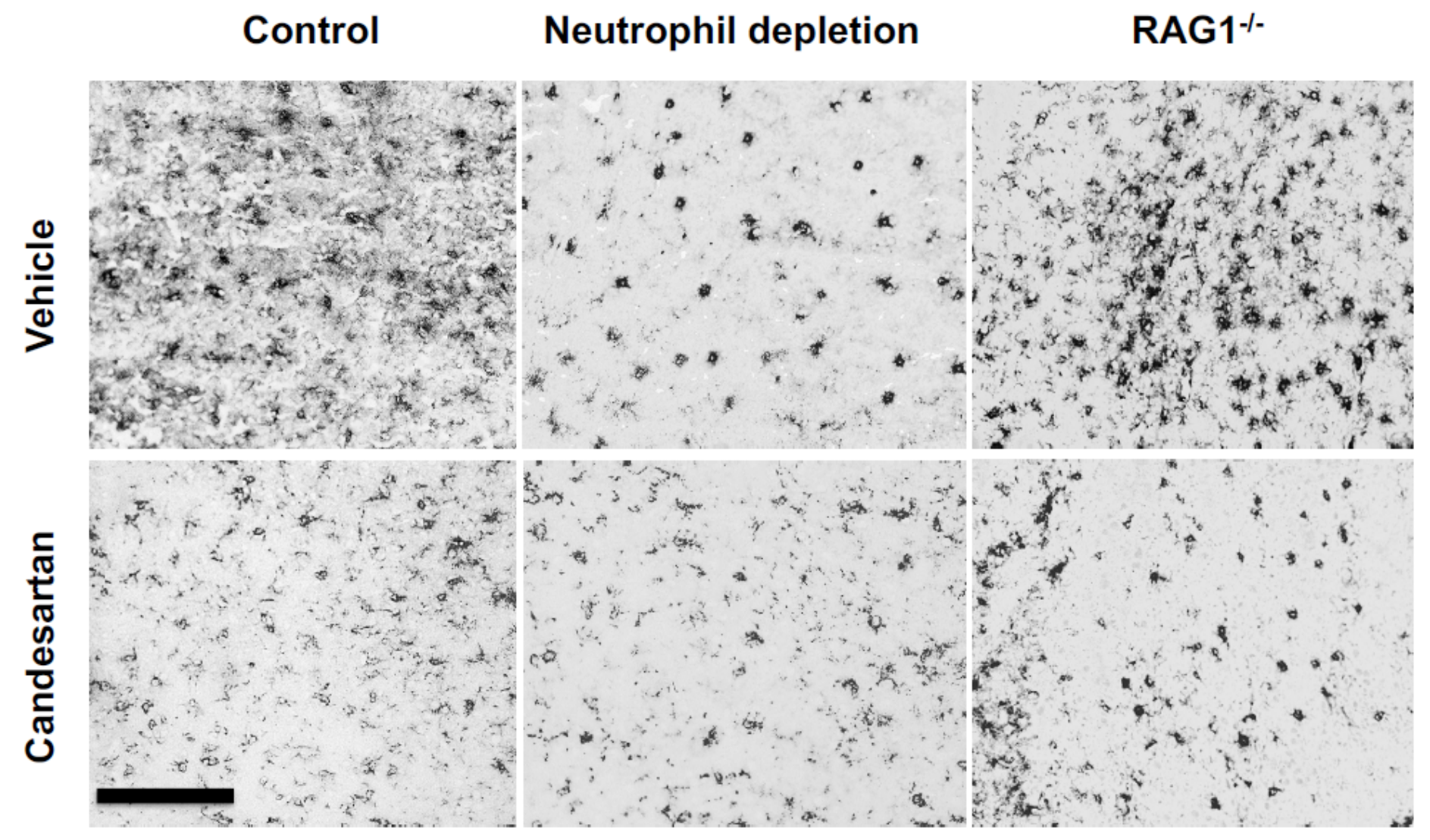

Figure 5

Representative images of Iba-1 stained sections. Representative immunohistochemistry images of Iba-1stained sections taken from an ipsilateral region of interest at bregma $-1.28 \mathrm{~mm}$, adjacent to the lesion (scale bar: $100 \mu \mathrm{m}$ ). Microglial acti-vation was analyzed three days after TBI. Images are presented as follows: upper row sections of vehicle treated, in the lower row sections of candesartan treated mice; left column sections of control antibody IgG2a (2A3) treated mice (with normal neutrophil count), in the middle column sections neutrophil depleted (anti-Ly6G (1A8) treated) mice and in the right column sections of lymphopenic RAG1-/- mice. 